HENRIQUE QUINTAS TEIXEIRA RIBEIRO

\title{
PAPEL DA VIA DO TLR-4 DEPENDENTE DO MYD88 NA INFLAMAÇÃO DO TECIDO ADIPOSO SUBCUTÂNEO DE PACIENTES COM CÂNCER E CAQUEXIA
}

\begin{abstract}
Dissertação apresentada ao Programa de Pós-Graduação em Biologia Celular e Tecidual do Instituto de Ciências Biomédicas da Universidade de São Paulo, para obtenção do Título de Mestre em Ciências
\end{abstract}


HENRIQUE QUINTAS TEIXEIRA RIBEIRO

PAPEL DA VIA DO TLR-4 DEPENDENTE DO MYD88 NA INFLAMAÇÃO DO TECIDO ADIPOSO SUBCUTÂNEO DE PACIENTES COM CÂNCER E CAQUEXIA

Dissertação apresentada ao

Programa de Pós-Graduação em

Biologia Celular e Tecidual do Instituto de Ciências Biomédicas da Universidade de São Paulo, para obtenção do Título de Mestre em Ciências

Área de concentração: Biologia Celular e Tecidual

Orientadora: Profa. Dra. Marilia Cerqueira Leite Seelaender

Versão original 
DADOS DE CATALOGAÇÃO NA PUBLICAÇÃO (CIP)

Serviço de Biblioteca e Informação Biomédica do

Instituto de Ciências Biomédicas da Universidade de São Paulo

(2) reproduçăo total

Ribeiro, Henrique Quintas Teixeira.

Papel da via do TLR-4 dependente do MyD88 na inflamação do tecido adiposo subcutâneo de pacientes com câncer e caquexia / Henrique Quintas Teixeira Ribeiro. -- São Paulo, 2013.

Orientador: Profa. Dra. Marília Cerqueira Leite Seelaender.

Dissertação (Mestrado) - Universidade de São Paulo. Instituto de Ciências Biomédicas. Departamento de Biologia Celular e do

Desenvolvimento. Área de concentração: Biologia Celular e Tecidual. Linha de pesquisa: Caquexia associada ao câncer e metabolismo do tecido adiposo branco.

Versão do título para o inglês: The role of MyD88-dependent TLR-4 pathway in subcutaneous adipose tissue inflammation in cachectic cancer patients.

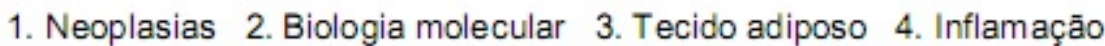
5. Citocinas 6. Expressão gênica I. Seelaender, Profa. Dra. Marilia Cerqueira Leite II. Universidade de São Paulo. Instituto de Ciências Biomédicas. Programa de Pós-Graduação em Biologia Celular e Tecidual III. Título. 
Candidato(a): $\quad$ Henrique Quintas Teixeira Ribeiro.

Título da Dissertação: $\quad$ Papel da via do TLR-4 dependente do MyD88 na inflamação do tecido adiposo subcutâneo de pacientes com câncer e caquexia.

Orientador(a): $\quad$ Profa. Dra. Marilia Cerqueira Leite Seelaender.

A Comissão Julgadora dos trabalhos de Defesa da Dissertação de Mestrado, em sessão pública realizada a ............................................, considerou
( ) Aprovado(a)
( ) Reprovado(a)

Examinador(a): Assinatura:

Nome:

Instituição:

Examinador(a): Assinatura:

Nome:

Instituição:

Presidente: Assinatura:

Nome:

Instituição: 
São Paulo, 30 de junho de 2011.

\section{PARECER 1003/CEP}

A Comissão de Ética em Pesquisas com Seres Humanos do ICB, na sessão realizada no dia 29.06.2011, APROVOU o projeto intitulado: "Papel da via do TLR-4 dependente do MyD88 nà inflamaçăo do tecido adiposo em pacientes caquéticos" sob responsabilidade de execução dos autores Profa. Dra. Marilia Cerqueira leite Seelaender e o aluno Henrique Quintas Teixeira Ribeiro.

Cabe a pesquisadora executante elaborar e apresentar a este Comitê, relatórios anuais ( parciais ou final), de acordo com a resolução $196 / 06$ do Conselho Nacional da Saúde, item IX. 2 letra c.

O primeiro relatório deverá ser encaminhado à Secretaria deste CEP em

\subsubsection{2.}

Atenciosamente,



Prof. Dr. PAOLO M.A.ZANOTTO

Coordenador da Comissão de Ética em

Pesquisas com Seres Humanos - ICB/USP 
São Paulo, 17 de setembro de 2007.

$I^{\text {mioial }} \cdot S^{\text {riaj }}$

Profa. Dra. Marilia Cerqueira Leite Seelaender

Grupo de Biologia Molecular da Célula

Departamento de Biologia Celular e do Desenvolvimento

Instituto de Ciências Biomédicas I

UNIVERSIDADE DE SÃO PAULO

REFERENTE: Projeto de Pesquisa "Infiuencia das citocinas pró e antiinflamatórias no tecido adiposo branco. Possivel interação entre adipócito e infiltrado mononuclear " - Co-Autor(es): Alex Shimura Yamashita; Paulo Sérgio Martins Alcântara - Registro CEP-HU/USP: 752/07 - SISNEP CAAE: 0031.0.198.019-07

Prezado(a) Senhor(a)

O Comitê de Ética em Pesquisa do Hospital Universitário da Lniversidade de Săo Paulo, em reunião ordinária realizada no dia 14 de setembro de 2007 , analisou o projeto de pesquisa acima citado, considerando-o como APROVADO, bem como, seu Termo de Consentimento Livre e Esclarecido.

Lembramos que cabe ao pesquisador elaborar e apresentar a este Comitê, relatórios anuais (parciais ou final, em função da duração da pesquisa), de acordo com a Resolução 196/96 do Conselho Nacional de Saúde, item IX.2 letra c.

O primeiro relatório está previsıo para 14 de setembro de 2008.

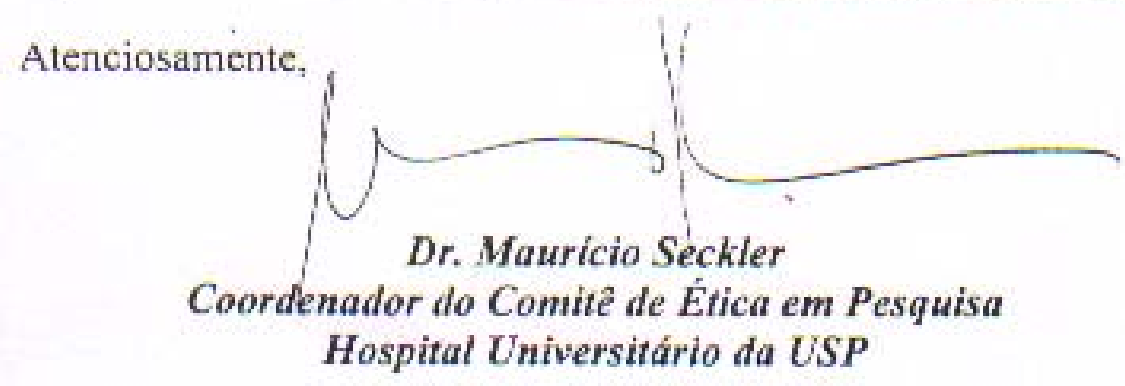




\section{PARECER 788/CEP}

Prezada Senhora,

Atendendo sua solicitaçăo, a Comissåo de Ética em Pesquisas com Seres Humanos do ICB, em sua $76^{\circ}$ reuniăo, realizada em 13.06.07, analisou o projeto de sua responsabilidade intitulado: "Influencia das citocinas pró- e antiinflamatónias no tecido adiposo branco. Possivel interaçăo adipócito e infiltrado mononuclear".

Informo a V.Sa, que, após análise e discussão, o referido projeto foi aprovado por esta Comissåo, condicionada a reformulaçăo do Termo de Consentimento Livre e Esclarecido, para proteção do grupo controle. Modelo anexo.

Lembramos que cabe ao pesquisador elaborar a apresentar a este Comitê, relatórios anuais (parciais ou final), de acordo com a fesoluçăo 196/0s do Consaiho Nacional da Saúde, item $\mathrm{X} \times 2$ letra $\mathrm{c}$.

O primeiro relatório deverá ser encaminhado à Secretaria deste CEP em

13 de junho de 2008.

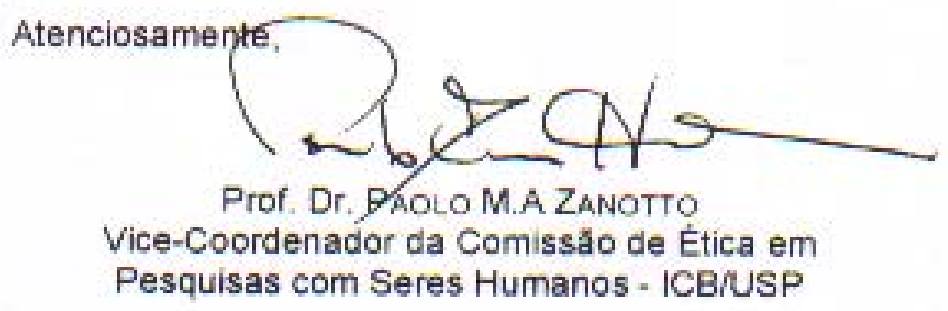

lima. Sra.

MARILIA CERQUEIRA L.SEELAENDER

Departamento de Biologia Celular e do Desenvolvimento

Instituto de Ciências Biomédicas -USP 
À Deus, por ter me dado uma família maravilhosa e saúde para trabalhar. 


\section{AGRADECIMENTOS}

Agradeço primeiramente a Deus, por ter me dado uma família maravilhosa, muitas alegrias e algumas situações que me fazem tentar ser sempre uma pessoa melhor.

Agradeço também a todos os colegas do laboratório, em especial Rodolfo Gonzalez Camargo, Luiz Carnevali, Waldecir Lima, Rodrigo Xavier das Neves, Jose Cesar Rosa Neto, Fernando de Oliveira Rosa, Felipe Donatto, Emidio Matos, Lucas Enjiu, Felipe Capel, Fabio Lira e Emilia Ribeiro; que contribuíram de alguma maneira para que esta dissertação pudesse ter sido realizada. Aos pacientes que aceitaram participar do projeto, aos profissionais da biblioteca pela atenção e pela agilidade, aos profissionais da secretaria, em especial Celiana e Regina, pelo auxílio imediato sempre que precisei, aos médicos do HU, em particular Dr. Paulo Sergio Martins Alcântara, Dra Linda Ferreira Maximiano e Dr. José Pinhata Otoch, pois sem eles simplesmente não seria possível coletar as amostras utilizadas, aos professor Ronaldo Tomatieli, bem como aos profissionais do laboratório RDO, pelo auxilio em alguns experimentos, e às professoras Alison Colquhoun, Maria Isabel Alonso Vale e novamente Linda Maximiano, por terem participado da minha banca de qualificação e dado sugestões e conselhos muito importantes para o desenvolvimento do estudo.

Obviamente agradeço muito à professora e minha orientadora Marilia Cerqueira Leite Seelaender por ter acreditado em meu trabalho, pelos elogios e também pelos "puxões de orelha". Chefe, com você aprendi muito!

A CAPES pelo auxilio financeiro.

Por fim, agradeço muito ao meu pai Fernando Manuel de Carvalho Teixeira Ribeiro, à minha mãe Angélica Maria de Jesus Quintas, aos meus irmãos Alexandre Quintas Teixeira Ribeiro e Eduardo Quintas Teixeira Ribeiro por serem tão bons para mim, e um agradecimento mais do que especial a duas pessoas que amo demais: minha filha Karina Sayuri Ribeiro e minha namorada Giovanna Corte Honda. Sempre penso em vocês, é por vocês que tenho forças para realizar o "impossível". 
"Não tente se tornar um homem de sucesso, mas sim um homem de valor". 


\section{RESUMO}

RIBEIRO, H. Q. T. Papel da via do TLR-4 dependente do MyD88 na inflamação do tecido adiposo subcutâneo de pacientes com câncer e caquexia. 2013. 71 f. Dissertação (Mestrado em Biologia Celular e Tecidual). - Instituto de Ciências Biomédicas, Universidade de São Paulo, São Paulo, 2013.

A caquexia associada ao câncer está presente na maioria dos pacientes com estágio avançado da doença e induz redução rápida e acentuada de peso, com franca depleção do tecido muscular esquelético e do tecido adiposo branco (TAB); além de estar associada ao estabelecimento de um estado inflamatório sistêmico. $O$ TAB é marcadamente afetado pela caquexia. Contudo, este tecido constitui também importante fonte de fatores pró-inflamatórios na vigência da síndrome. As citocinas pró-inflamatórias são apontadas como responsáveis pela ativação do catabolismo do TAB em modelos experimentais, acarretando elevada lipólise. A via do receptor Tolllike 4 (TLR-4) dependente do fator 88 de diferenciação mielóide (MyD88), passível da ativação por endotoxinas e ácidos graxos livres (AGL), poderia exercer um importante papel no aumento da inflamação dos pacientes portadores de câncer e caquexia, pois está ativada em outros quadros inflamatórios. Sendo assim, foi objetivo do estudo examinar o papel desta via no TAB subcutâneo de pacientes com hérnia, com câncer sem caquexia e com câncer e caquexia. Foram verificados parâmetros antropométricos e bioquímicos e as concentrações de citocinas próinflamatórias, tanto no tecido adiposo subcutâneo quanto no soro. Além disso, examinou-se a expressão gênica das proteínas TLR-4, MyD88 e TRAF-6 (componentes da via), além da proteína p65, da via do NFkB; posto que esta via é responsável pela indução de grande parte das citocinas pró-inflamatórias. Utilizou-se amostras de 45 pacientes, sendo 20 do grupo controle (cirurgia de hérnia), 14 do grupo câncer sem caquexia (TsC) e 11 do grupo câncer com caquexia (TcC). O grupo TcC consistiu de pacientes que relataram perda de peso não intencional superior a $5 \%$ durante os seis meses prévios à aplicação do questionário; além de fadiga, depressão e dor. Além disso, apresentaram inflamação sistêmica (ou seja, $\mathrm{PCR} \geq 10 \mathrm{mg} / \mathrm{L}$ e/ou albumina $\leq 35 \mathrm{~g} / \mathrm{L}$ ). O grupo TsC consistiu de pacientes que não apresentaram perda de peso superior a $5 \%$ nos seis meses prévios à cirurgia, tampouco inflamação sistêmica, mas que tinham câncer. Os resultados dos parâmetros bioquímicos apontaram conteúdos de glicerol $(p=0,003)$, colesterol $(p=$ $0,013)$, triacilglicerol $(p=0,033)$, ácidos graxos livres (AGLs) $(p=0,026)$ aumentados no grupo TcC, além de menor concentração de HDL ( $p=0,0003)$ no mesmo grupo em relação aos grupos $\mathrm{TsC}$ e controle. Em relação às citocinas pró-inflamatórias, verificou-se aumento nas concentrações de TNF- $\alpha$ no soro $(p=0,0416)$ e no TAB subcutâneo ( $p=0,0066)$ e também de IL-6 nos mesmos sítios ( $p=0,0029$ no soro e $p=0,003$ no TAB subcutâneo) no grupo TcC em relação aos demais; houve ainda incremento na expressão gênica das proteínas estudadas: TLR-4 ( $p=0,0155)$, MyD88 ( $p=0,0143)$, TRAF-6 ( $p=0,0339)$, p65 ( $p=0,0353)$. Os dados sugerem que essa via pode apresentar um importante papel na inflamação característica da caquexia.

Palavras-chave: Caquexia. Câncer. Tecido adiposo branco. Inflamação. Receptor toll-like 4 (TLR-4). 


\begin{abstract}
RIBEIRO, $H$. Q. T. The role of MyD88-dependent TLR-4 pathway in subcutaneous adipose tissue inflammation in cachectic cancer patients. 2013. 71 p. Masters thesis (Celular and Tissue Biology) - Instituto de Ciências Biomédicas, Universidade de São Paulo, São Paulo, 2013.
\end{abstract}

Cancer cachexia is present in most of the patients with advanced cancer, and induces a marked and fast reduction of weight, with skeletal muscle tissue and white adipose tissue (WAT) depletion; and is associated with chronic systemic inflammation. WAT is remarkably affected by cachexia. However, this tissue also constitutes an important source of pro-inflammatory cytokines contributing for the development of the syndrome. Pro-inflammatory cytokines are pointed out to be responsible for WAT catabolism in experimental models, leading to increased lipolysis. The myeloid differentiation primary response 88 (MyD88) dependent Tolllike receptor 4 (TLR-4) pathway is activated either by endotoxin or non-esterfied fatty acids (NEFA), and could modulate cachexia-related inflammation. Thus, the objective of this study was to examine the role of MyD88-dependent TLR-4 pathway in the subcutaneous WAT of patients with hernia (controls), with cancer and cachexia, and with cancer in the absence of cachexia. Anthropometric and biochemical features were assessed, as well as pro-inflammatory cytokine levels in the serum and in subcutaneous WAT. Gene expression of TLR-4, MyD88 and TRAF-6 proteins (components of the pathway) was evaluated, as well as of p65 protein, a subunit of NFkB pathway. The study involved 45 patients, 20 in the control group, 14 in the tumour without cachexia group (TsC) and 11 in the cancer cachectic group (TcC). The cachectic cancer group consisted of patients who declared non-intentional weight loss of more than $5 \%$ in six months previous to the application of questionnaires and also fatigue, depression and pain. These patients presented systemic inflammation (C-reactive protein $\geq 10 \mathrm{mg} / \mathrm{L}$ and/or albumine $\leq 35 \mathrm{~g} / \mathrm{L}$ ). The group of patients with cancer without cachexia consisted of patients who did not show either weight loss over $5 \%$ in the previous six months or systemic inflammation, but had cancer. Biochemical parameters indicated a higher concentration of glycerol $(p=0.003)$, cholesterol $(p=0.013)$, triacylglycerol $(p=0.033)$, and non-esterified fatty acids (NEFA) ( $p=0.026)$ in TcC group, and diminished HDL content $(p=$ 0.0003 ), compared with TsC and control. A higher content of TNF-alpha in the serum $(p=0.0416)$ and in the subcutaneous WAT $(p=0.0066)$ was found in TcC, as well as of IL-6 ( $p=0.0029$ in the serum and $p=0.003$ in the tissue) in comparison both controls; An increase in the gene expression of the studied proteins: TLR-4 ( $p=$ $0.0155)$, MyD88 ( $p=0.0143)$, TRAF-6 ( $p=0.0339), p 65(p=0.0353)$ was also found for TcC. The data suggest that this pathway is possibly associated with the modulation of inflammation in cachexia.

Keywords: Cachexia. Cancer. White adipose tissue. Inflammation. Toll-like receptor (TLR-4). 


\section{LISTA DE FIGURAS}

Figura 1 - Via do TLR-4 dependente e independente do MyD88.

Figura 2 - Expressão das citocinas TNF- $\alpha$, IL-6 e IFN-y no soro. (A) a expressão de TNF- $\alpha,(B)$ expressão de IL-6 e (C) expressão de IFN-Y 40

Figura 3 - Expressão das citocinas TNF- $\alpha$, IL-6 e IFN-y no tecido. (A) a expressão de TNF-a, (B) expressão de IL-6 e (C) expressão de IFN-Y

Figura 4 - Expressão gênica das proteínas TLR-4, MyD88, TRAF-6 e p65. (A) expressão gênica de TLR-4, (B) expressão gênica de MyD88, (C) expressão gênica de TRAF-6 e (D) expressão gênica de p65.

Figura 5 - Ilustração da hipótese formulada. 


\section{LISTA DE TABELAS}

Tabela 1 - Referências e resultados de estudos realizados por nosso laboratório que caracterizaram a influência do tecido adiposo para a inflamação

Tabela 2 - Primers utilizados para a amplificação dos genes de interesse, a partir das sequências disponíveis no GenBank

Tabela 3 - Características gerais e parâmetros antropométricos dos pacientes......38

Tabela 4 - Características bioquímicas dos pacientes por grupo 39 


\section{LISTA DE ABREVIATURAS E SIGLAS}

$\mathrm{TAB}$

TLR-4

MyD88

AGL

TRAF-6

NFKB

$\mathrm{TsC}$

$\mathrm{TcC}$

HIV

IL-1 $\beta$

IL-6

$\mathrm{IL}-10$

TNF- $\alpha$

IFN-Y

PCR

MCP-1

LHS

ATGL

TLRs

PAMPs

DAMPs

LPS

IRAK-4

IRAK-1

IRF-3

IFN- $\beta$

MAPKs

HU - USP

ICB

SIDA

TCLE

IMC
Tecido adiposo branco

Receptor Toll-like 4

Fator 88 de diferenciação mielóide

Ácidos graxos livres

Fator 6 associado ao receptor de TNF

Fator de transcrição kappa B

Tumor sem caquexia

Tumor com caquexia

Vírus da imunodeficiência humana

Interleucina 1-beta

Interleucina 6

Interleucina 10

Fator de necrose tumoral alfa

Interferon gamma

Proteína C-reativa

Proteínas quimioatraentes de monócitos 1

Lipase hormônio sensível

Triacilglicerol lipase

Receptores Toll-like

Moléculas com padrão molecular associadas a patógenos

Moléculas com padrão molecular associadas a danos

Lipopolissacarídeos

Kinase 4 associada ao receptor de interleucina 1

kinase 1 associada ao receptor de interleucina 1

Fator de transcrição regulador do interferon 3

Interferon beta

Proteínas-quinases ativadas por mitógenos

Hospital Universitário da Universidade de São Paulo

Instituto de Ciências Biomédicas

Síndrome da imunodeficiência adquirida

Termo de consentimento livre e esclarecido

Índice de massa corporal 
RPM

HDL

LAL

RNA

qPCR

DEPC

cDNA

TLR-2

iNOS

RIPA
Rotações por minuto

Lipoproteína de alta densidade

Lisado de Amebócitos do Limulus

Ácido ribonucleico

Reação em cadeia de polimerase quantitativa em tempo real

Dietilpirocarbonato

Ácido desoxirribonucléico complementar

Receptor Toll-like 2

Óxido nítrico sintetase induzível

Radioimunoprecipitação 


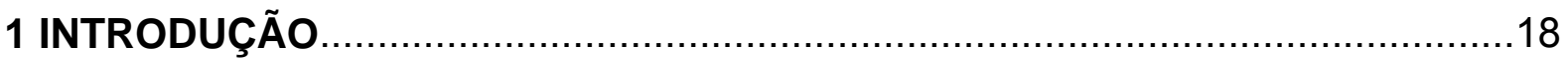

1.1 Caquexia associada ao câncer........................................................

1.2 Relação entre o tecido adiposo e a caquexia .........................................19

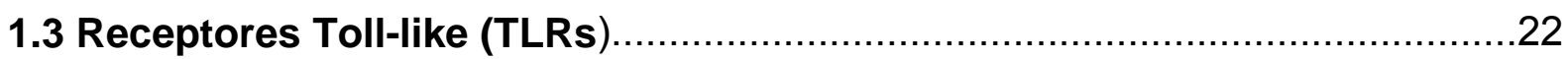

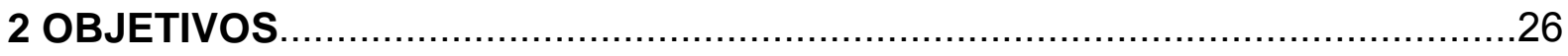

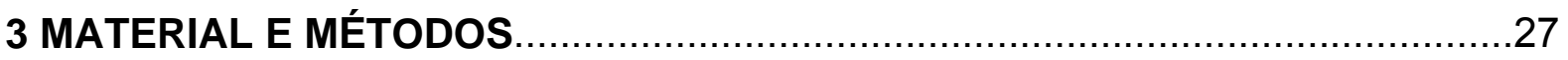

3.1 Recrutamento dos pacientes e seleção das amostras.............................27

3.2 Aprovação no Comitê de Ética ......................................................... 27

3.3 Critérios de inclusão e exclusão dos diferentes grupos.........................28

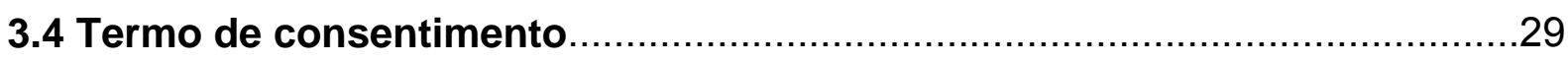

3.5 Características gerais e parâmetros antropométricos...............................29

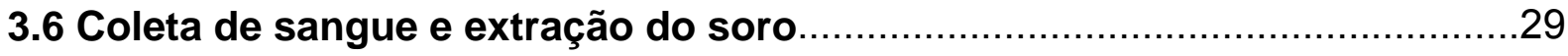

3.7 Parâmetros bioquímicos analisados no soro dos pacientes.....................29

3.7.1 Hemoglobina, uréia, glicose e creatinina .............................................29

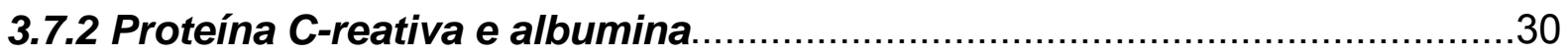

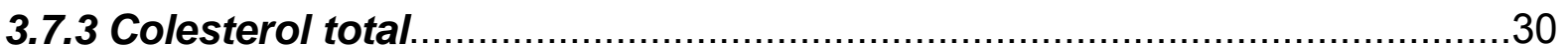

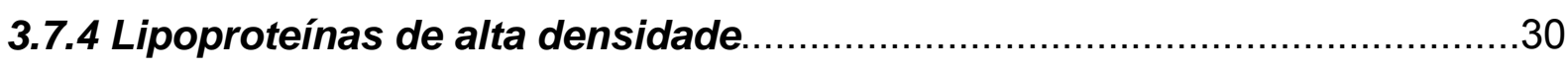

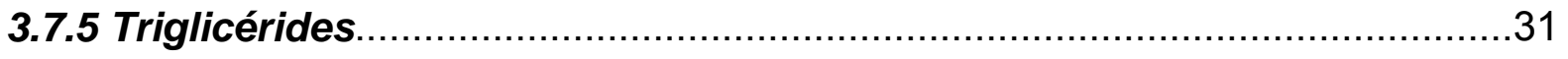

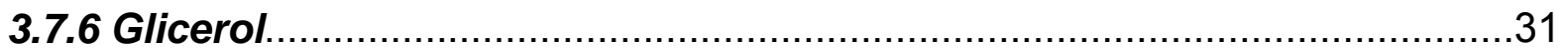

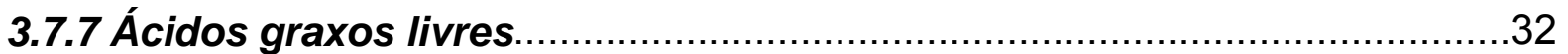

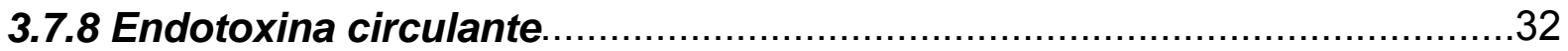

3.7.9 Quantificação de proteínas específicas................................................33



3.9 Medida da expressão gênica por PCR tempo real..................................34

3.10 Extração de proteínas e quantificação de proteínas totais.........................36

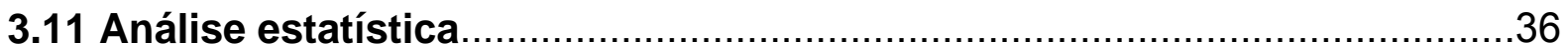

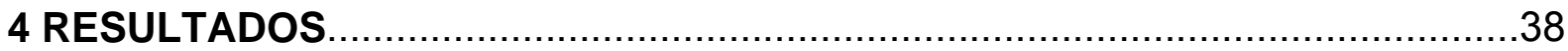

4.1 Avaliação dos parâmetros antropométricos.........................................38

4.2 Avaliação dos parâmetros bioquímicos...............................................

4.3 Avaliação da expressão de citocinas no soro.......................................39

4.4 Avaliação da expressão de citocinas no tecido adiposo...........................41

4.5 Expressão gênica das proteínas de interesse....................................42 


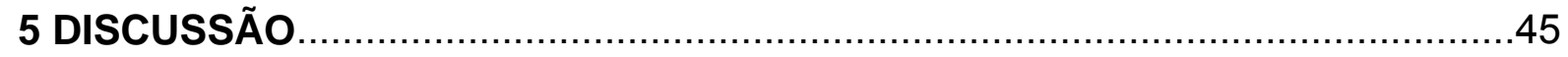

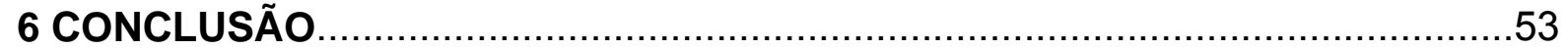



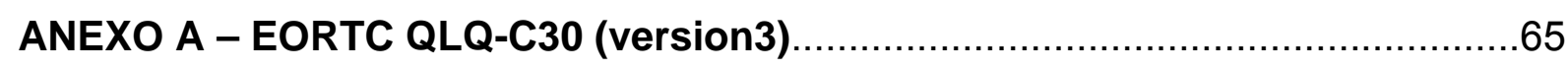

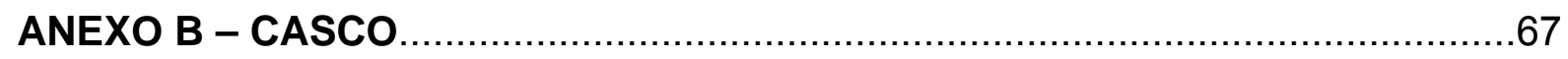

ANEXO C - Termo de consentimento livre e esclarecido (TCLE) ..................70 


\section{INTRODUÇÃO}

\subsection{Caquexia associada ao câncer}

A caquexia associada ao câncer, cujo sintoma mais marcante é uma rápida e acentuada diminuição de peso corporal (AGUSTSSON et al., 2007), é caracterizada por uma depleção de massas magra (músculo esquelético) e gorda (tecido adiposo branco (TAB)) (BATISTA JUNIOR et al., 2012; TISDALE, 1999); além de outros sintomas, como astenia e anemia (CANNON et al., 2007). Esta síndrome paraneoplásica afeta cerca de metade dos pacientes com câncer e está presente na maioria (mais de dois terços) dos pacientes com câncer avançado (ARGILÉS; ALVAREZ; LÓPEZ-SORIANO, 1997; BING; TRAYHURN, 2008; FEARON; MOSES, 2002), sendo responsável direta por 20 a 40 por cento de todos os óbitos quando associada ao câncer (ARGILÉS; LÓPEZ-SORIANO; BUSQUETS, 2008).

A palavra "caquexia" é originada do grego, em que kakos e hexis significam "má" e "condição", respectivamente (ARGILÉS; ALVAREZ; LÓPEZ-SORIANO, 1997). A síndrome resulta em reduzida qualidade de vida, diminuição de sobrevida e aumento de complicações associadas à quimio e radioterapia.

Até a década de 80 , as perdas associadas à caquexia eram atribuídas à anorexia induzida por fatores produzidos pelo tumor, e também pelo aumento do gasto energético basal. Terapias nutricionais, no entanto, falham sistematicamente na tentativa de reverter estes sintomas (TISDALE, 2009). Desta forma, desde o final dos anos 80 , a caquexia é caracterizada como uma síndrome inflamatória crônica (ROSS, 1999) que evolui a partir da interação entre o tumor e o hospedeiro (BRUERA et al., 1997; DELANO; MOLDAWER, 2006; TISDALE, 1999; TISDALE, 2004), levando a um desequilíbrio que favorece o catabolismo em relação ao anabolismo. Além disso, está associada à alteração do metabolismo de carboidratos, lipídeos e proteínas (BENNANI-BAITI; DAVIS, 2008).

Embora certos tipos de tumor sejam mais comumente associados à caquexia, mesmo em relação a um mesmo tipo de câncer pode existir variação na prevalência (TAN et al., 2011). Pacientes com câncer gástrico ou pancreático apresentam a maior prevalência de caquexia (DEWYS, 1986), sendo mais de $85 \%$ dos pacientes com câncer de pâncreas caquéticos (TISDALE, 2000). 


\subsection{Relação entre o tecido adiposo e a caquexia}

O tecido adiposo branco (TAB), além de servir como sítio de armazenamento de energia sob a forma de triglicérides (ZHANG et al., 1994), também é reconhecido como um importante órgão endócrino, uma vez que sintetiza e secreta uma grande quantidade de hormônios e sinais protéicos e lipídicos (FANTUZZI, 2005). Além disso, também secreta mediadores pró-inflamatórios e responde aos mesmos, expressando uma pletora de receptores para citocinas, quimiocinas e fatores de complemento e crescimento (ARNER, 2003). As adipocinas atuam localmente de maneira autócrina/parácrina e/ou como sinais endócrinos no organismo para regulação do apetite, modulação do gasto de energia e de uma gama de processos fisiológicos, incluindo controle da sensibilidade à insulina, bem como na resposta inflamatória (KEREM et al., 2008). Agustsson et al. (2007) e Ryden et al. (2008) propuseram que um desequilíbrio entre os processos catabólico e anabólico no tecido está associado à progressão da caquexia; tendo Argilés, Busquets e LópezSoriano (2003) apontado a interleucina 1-beta (IL-1ß), a interleucina 6 (IL-6), o fator de necrose tumoral alfa (TNF- $\alpha$ ) e o interferon gama (IFN- $\gamma$ ), todas citocinas próinflamatórias, como responsáveis pela ativação do catabolismo do TAB em modelos experimentais.

$\mathrm{Na}$ caquexia, assim como em outros quadros inflamatórios, o tecido adiposo sofre vasta lipólise, em decorrência de uma maior expressão gênica e protéica das enzimas lipase hormônio sensível (LHS) (AGUSTSSON et al., 2007) e triacilglicerol lipase (ATGL) (BING, 2011); e em concomitância à influência de fatores próinflamatórios sobre o tecido (SUGANAMI; OGAWA, 2010), aumentando a quantidade de ácidos graxos livres no sangue. Em um estudo prévio realizado por nosso laboratório (MACHADO; COSTA ROSA; SEELAENDER, 2004), foi verificada a presença de um importante infiltrado de macrófagos no tecido adiposo de ratos com câncer e caquexia, que demonstrou contribuir para a secreção de fatores inflamatórios atribuída a este tecido. Suganami et al. (2007) demonstraram em um estudo com sistema de co-cultura composto por adipócitos e macrófagos, um ciclo vicioso entre ácidos graxos livres e TNF- $\alpha$ (derivados respectivamente dos adipócitos e macrófagos), que aumentou a regulação de citocinas pró-inflamatórias e

diminuiu a produção de citocinas anti-inflamatórias, conduzindo os autores a especular que os macrófagos, quando infiltrados em grande número no tecido 
adiposo, induzem a liberação de ácidos graxos livres pelo adipócito, que por sua vez, servem como indutores da expressão de citocinas pró-inflamatórias nesse mesmo sítio. Mohamed-Ali, Pinkney e Coppack (1998) por sua vez apontaram que as estas citocinas podem não somente atuar localmente, mas também em adipócitos próximos ou até mesmo em outros tecidos, por migrarem para a corrente sanguínea. Recentemente, nosso grupo (BATISTA JUNIOR et al., 2013) verificou que no TAB de pacientes caquéticos também há ocorrência de um infiltrado imunitário, envolvido na inflamação local no tecido adiposo. Por estas razões, é possível que o tecido adiposo contribua significativamente para o aumento da inflamação verificado na caquexia.

O TNF- $\alpha$ apresenta papel fundamental nos efeitos deletérios promovidos pela caquexia (revisto por LIRA et al., 2009). Esta citocina é uma das principais responsáveis pela perda de peso, degradação de proteínas da musculatura esquelética e elevado gasto energético em animais e pacientes (O'RIORDAIN et al., 1999). No tecido adiposo, induz um aumento na taxa da lipólise em pacientes (RYDEN et al., 2002), ratos (BOTION et al., 2001) e em cultura de adipócitos 3T3-L1 (OGAWA; NIELSEN; KAWAKAMI, 1989).

Além de estar envolvido na regulação metabólica, fisiológica e imunológica do tecido adiposo, o TNF- $\alpha$ apresenta papel primário em relação à produção de diversas citocinas, como da interleucina 10 (IL-10) e de adipocinas, como a leptina (COPPACK, 2001; TRAYHURN; WOOD, 2005), e é a principal citocina estudada neste tecido (MONTAGUE, 2002). Recentemente a razão IL-10/TNF- $\alpha$ foi adotada como marcador da intensidade da condição inflamatória tanto em animais (LIRA et al., 2009) quanto em indivíduos (JUNG et al., 2008); considerando-se que quanto menor o valor da razão, maior a diminuição nas chances de sobrevivência (ESPOSITO et al., 2003).

Diante deste contexto, em que o tecido adiposo tanto é afetado quanto contribui ativamente para os efeitos da caquexia, nosso grupo tem-se dedicado a caracterizar a contribuição do tecido adiposo para a inflamação característica desta síndrome (Tabela 1). 
Tabela 1 - Referências e resultados de estudos realizados por nosso laboratório que caracterizaram a influência do tecido adiposo para a inflamação.

\begin{tabular}{ll}
\hline REFERÊNCIAS BIBLIOGRÁFICAS & \multicolumn{1}{c}{ RESULTADOS } \\
\hline Bertevello e Seelaender, 2001 & $\begin{array}{l}\text { Ratos caquéticos apresentaram } \\
\text { alterações de parâmetros bioquímicos } \\
\text { e morfológicos do tecido adiposo em } \\
\text { comparação a ratos sem caquexia }\end{array}$ \\
\hline Machado, Costa Rosa e Seelaender, & \begin{tabular}{l} 
Verificou-se a presença de infiltrado \\
de macrófagos no tecido adiposo, e \\
também uma possível relação entre \\
maior produção de TNF-a e menor \\
produção de leptina no tecido adiposo \\
de ratos caquéticos \\
\hline O tecido adiposo subcutâneo de \\
pacientes com câncer aparentemente \\
está associado com a produção de \\
fatores inflamatórios, que podem atuar \\
como marcadores da caquexia
\end{tabular} \\
\hline
\end{tabular}

Barnes e Karin (1997) apontaram que um ponto chave na regulação da inflamação, em nível celular, é a ativação da via do fator de transcrição nuclear kappa B (NFkB), pois esta é responsável pelo controle de transcrição das citocinas envolvidas na etiologia da caquexia; e Garg e Aggarwal (2002) que há evidências que indicam a ligação entre a inflamação promovida pela ativação desse fator de transcrição e o câncer. A via do NFKB pode ser ativada por diversos estímulos ligados à inflamação, como o TNF- $\alpha$ e a IL-1 $\beta$ (SCHWARTZ; HERNANDEZ; MARK EVERS, 1999); e é sabido que a ativação dos receptores Toll-like também é responsável por regular esta via, sendo um importante contribuinte para a modulação da inflamação (KAWAl; AKIRA, 2007). 


\subsection{Receptores Toll-like (TLRs)}

Desde a década de 90 , o fato de o tecido adiposo contribuir para a função imunitária é cada vez mais evidente (KOPP et al., 2010). O sistema imune inato representa a primeira linha de defesa contra a infecção, mas, ao contrário da resposta imunitária adaptativa, que depende de linfócitos, é conhecido por atuar através da família de receptores Toll-like (TLRs) (CREELY et al., 2007). Até o presente momento foram identificados 12 membros da família destes receptores em mamíferos (ABREU; ARDITI, 2004), encontrados em diversos tipos celulares, incluindo macrófagos, células dendríticas $T$ e $B$, tumorais, musculares e adipócitos (KOPP; MEDZHITOV, 1999), além de neutrófilos (MICHELSEN et al., 2004).

Os TLRs constituem uma família de receptores de reconhecimento padrão que desempenham um papel fundamental no sistema imunológico inato, pois ativam vias de sinalização pró-inflamatórias em resposta a sinais de "perigo" referidos como PAMPs (moléculas com padrão molecular associado a patógenos), e DAMPs (moléculas com padrão molecular associado a danos) (ZHU; MOHAN, 2010). A sinalização através da via dos TLRs não resulta somente na imunidade específica ao antígeno (ALEXOPOULOS et al., 2002; KRUTZIK et al., 2003), mas leva também à produção de citocinas relacionadas à inflamação, como observado em doenças cardiovasculares, diabetes tipo II e artrite reumatóide (TAKEDA; AKIRA, 2005). Segundo Vitseva et al. (2008), os TLRs são capazes de ativar a via do fator nuclear kappa B (NFKB), envolvida na liberação de citocinas pró-inflamatórias a partir do tecido adiposo, entre outros, como observado em animais e seres humanos (KANAYAMA et al., 2004). Pelo fato de a maioria dos TLRs ser expressa no tecido adiposo de roedores (TLR-1 até TLR-9) (BATRA et al., 2007) e dos genes de TLR-1, TLR-2, TLR-4, TLR-7 e TLR-8 serem encontrados no tecido adiposo de humanos (VITSEVA et al., 2008), sugere-se que o tecido apresente papel dinâmico tanto nas respostas imunológicas inatas ou adaptativas quanto na produção de citocinas próinflamatórias em diversos casos de doenças crônicas.

Os receptores Toll-like 4 (TLR-4) foram os primeiros receptores identificados da família dos TLRs e os mais estudados nos mamíferos (MALLARD, 2012). São encontrados em células como adipócitos, hepatócitos, miócitos e macrófagos (LANG et al., 2003), podendo ser ativados tanto por lipopolissacarídeos (LPS) quanto por agonistas não bacterianos, como os ácidos graxos saturados (HUSSEY et al., 2012). 
Estudos apontam uma relação direta entre a atividade do TLR-4 e o aumento da inflamação no tecido adiposo subcutâneo em diferentes condições inflamatórias, como na obesidade (VITSEVA et al., 2008), resistência à insulina (SHI et al., 2006) e no exercício exaustivo (ROSA NETO et al., 2010). LPS são componentes de bactérias Gram-negativas, e estimulam respostas do sistema imunológico e inflamatórias que acarretam a ativação do TLR-4 nas células dos mamíferos (MILLER; ERNST; BADER, 2005)

Segundo Suganami et al. (2007), os ácidos graxos livres provenientes da lipólise estimulam o aumento na translocação para o núcleo do NFKB, mediada pela via do TLR-4, tendo Rosa Neto et al. (2010) verificado que no exercício exaustivo, o aumento na lipólise e conseqüentemente a maior liberação de ácidos graxos são o principal estímulo do incremento do fluxo da via, assim como também relatado para indivíduos obesos, em que os AGLs também ativam a via do TLR-4 em células adiposas e em macrófagos (VITSEVA et al., 2008). Agustsson et al. (2007) verificaram lipólise significativamente aumentada em pacientes com câncer e caquexia, gerando uma maior quantidade de ácidos graxos circulantes ou no interstício, que por sua vez podem aumentar o fluxo na via do TLR-4.

Quando o TLR-4 é ativado, ocorre um estímulo da proteína adaptadora MyD88 (fator 88 de diferenciação mielóide) e o recrutamento da proteína IRAK-4 (kinase 4 associada ao receptor de interleucina 1), facilitando a fosforilação da proteína IRAK-1 (kinase 1 associada ao receptor de interleucina 1), que por sua vez se associa à proteína TRAF-6 (fator 6 associado ao receptor de TNF), acarretando a ativação da via do NFKB, e consequente aumento da expressão gênica de citocinas pró-inflamatórias (TAKEDA; AKIRA, 2005). Esta via é chamada de via do TLR-4 dependente do MyD88.

Além da via dependente do MyD88, a via independente do MyD88 também é estimulada após a ativação do TLR-4. Uma vez ativada, esta via leva à ativação do fator de transcrição regulador do interferon 3 (IRF-3), que por sua vez leva à produção da proteína interferon beta (IFN- $\beta$ ). Para que ocorra a produção de citocinas pró-inflamatórias, necessariamente a via do TLR-4 dependente do MyD88 deve estar ativada (SCHNARE et al., 2000). As vias do TLR-4 dependente e independente do MyD88 estão ilustradas na figura 1. 
Figura 1 - Via do TLR-4 dependente e independente do MyD88

Dependente do MyD88

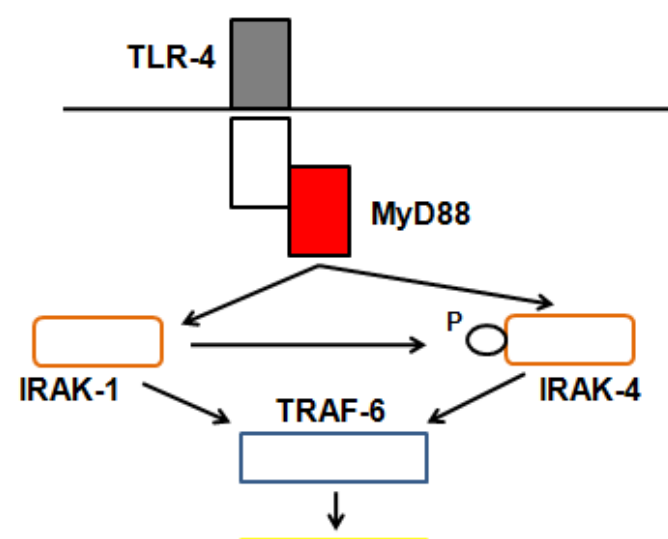

NFkB

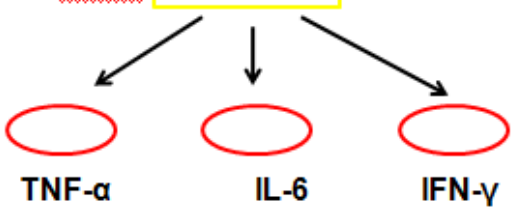

Independente do MyD88

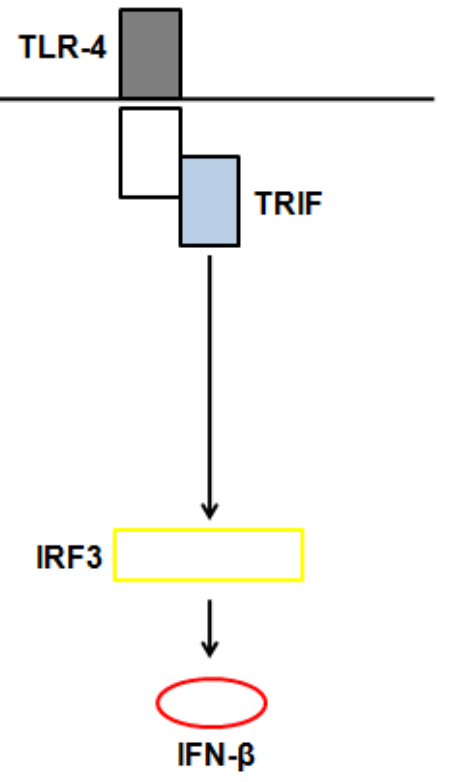

Fonte: Adaptada de Takeda e Akira (2005)

Oshima e Oshima (2012) mostraram que a ativação da via do TLR-4 dependente do MyD88 em células cancerígenas acarretou a proliferação do tumor, sendo a via, sendo a via capaz de mediar a indução de citoxinas pró-inflamatórias. Creely et al. (2007) e Fogelstrand et al. (2004) demonstraram que o TLR-4 está envolvido na indução de citocinas pró-inflamatórias em outras células, como macrófagos e adipócitos.

Triantafilou et al. (2004) apontaram que a ligação do LPS foi capaz de ativar diversas moléculas de sinalização, como as proteínas-quinases ativadas por mitógenos (MAPKs), JNK/SAPK, p38 e NFKB; fato verificado também por Küper, Beck e Neuhofer (2011) em macrófagos. O NFKB é capaz de induzir a transcrição de genes de citocinas, quimiocinas e moléculas de adesão, sendo estes fundamentais para o início da resposta inflamatória e recrutamento de células do sistema imunológico (BARNES; KARIN, 1997). Zhang e Ghosh (2001) apontaram que a via ativada pelo TLR-4 mais bem caracterizada na literatura é a do NFKB, que representa um componente crítico do sistema imune inato (O’NEILL; GREENE, 1998). 
A via do NFKB aparenta ser muito importante na caquexia, uma vez que é ativada não só pela via do TLR-4, mas também pela via ativada pela ligação do TNF- $\alpha$ ao seu receptor (FRASER, 2006). Wu et al. (2007) ressaltaram a efetividade na inibição da ativação desta via na redução da síntese de citocinas próinflamatórias. Entretanto, Fong et al. (2008) verificaram que a proteína IKKß, que faz parte da via clássica do $\mathrm{NFKB}$, era capaz de inibir a ativação de macrófagos $M 1$, podendo estar relacionada à resolução da inflamação. Independentemente de contribuir aumentando ou atenuando a inflamação, a possibilidade desta via estar ativada na caquexia é real.

Davis et al. (2008) demonstraram no tecido adiposo de obesos uma correlação positiva entre TLR-4, proteína quimiotática de monócitos-1 (MCP-1), infiltração de macrófagos, e conteúdo de NF-kB. Além disso, Kopp et al. (2009) verificaram o papel da via do TLR-4 em adipócitos para a regulação da secreção de MCP-1 no tecido adiposo e ativação do NF-kB.

Com base nas informações apresentadas ao longo da introdução, pode-se afirmar que a caquexia é uma síndrome caracterizada por uma inflamação crônica, que apresenta um elevado conteúdo de citocinas pró-inflamatórias tanto no tecido adiposo quanto no sangue. $O$ tecido adiposo, ao mesmo tempo em que sofre conseqüências decorrentes do alto conteúdo de fatores inflamatórios, como a migração de células do sistema imune, inflamação e lipólise, é também capaz de secretar estes fatores; e por esta razão contribui ativamente para a degradação promovida pela síndrome nos tecidos. A via do TLR-4 dependente do MyD88 é ativada por LPS e AGLs no tecido adiposo de pacientes que apresentam alto grau de inflamação em outros quadros inflamatórios que não a caquexia, sendo capaz de desencadear uma maior produção de citocinas por este tecido a partir da ativação de vias como as MAPKs, JNK/SAPK, p38 e principalmente NFKB. Apesar disso, até o presente momento não existem dados consistentes que apontem alguma relação entre o papel desta via no tecido adiposo de pacientes com câncer e caquexia e a inflamação que assola estes pacientes, seja ela local ou sistêmica. Sendo assim, os objetivos deste estudo serão apresentados na próxima seção. 


\section{OBJETIVOS}

\subsection{Geral}

> Examinar a relevância da via do TLR-4 dependente do MyD88 na inflamação do tecido adiposo subcutâneo de pacientes portadores de caquexia associada ao câncer.

\subsection{Específicos}

> Verificar parâmetros antropométricos e bioquímicos dos pacientes, com o intuito de diagnosticar a caquexia e formar os grupos;

Verificar não só no tecido adiposo subcutâneo, mas também no soro, a concentração de TNF-a, IL-6 e IFN-y dos pacientes caquéticos;

Considerando-se que a via do TLR-4 dependente do MyD88 está associada à inflamação, verificar se há modulação da expressão gênica das proteínas TLR-4 MyD88, TRAF6 (respectivamente primeira e última proteínas da via); e da subunidade p65 do NFkB, na caquexia. 


\section{MATERIAL E MÉTODOS}

\subsection{Recrutamento dos pacientes e seleção das amostras}

Inicialmente foram recrutados mais de 100 pacientes no Hospital Universitário da Universidade de São Paulo (HU - USP), entre os meses de Julho de 2010 e Julho de 2011. O recrutamento foi realizado por médicos envolvidos no projeto, e consistiu em uma seleção inicial de pacientes que seriam submetidos a cirurgias de hérnia (grupo controle) e cirurgias relacionadas a neoplasias gástricas (sendo estes pacientes divididos em dois grupos, sendo um de pacientes com tumor e sem caquexia e outro com tumor e caquexia). O critério de adoção para o diagnóstico da neoplasia foi aquele preconizado pelo Instituto Nacional do Câncer (2004), relativo a tumores de esôfago, fígado, vesícula biliar, ampola de Vater, pâncreas, estômago, intestino delgado, cólon e reto.

Após a seleção inicial dos pacientes, foi realizada uma segunda etapa seletiva, baseada nos critérios de inclusão e exclusão (citados no item 3.3) dos três diferentes grupos, de maneira que foram utilizadas amostras de 45 pacientes, sendo 20 pertencentes ao grupo controle, 14 do grupo com tumor e sem caquexia (TsC) e 11 do grupo com tumor e caquexia (TcC).

\subsection{Aprovação no Comitê de Ética}

O presente projeto foi aprovado pelo Comitê de Ética e Pesquisa do ICB envolvendo seres humanos, a partir do PARECER 1003/CEP. O presente projeto é ainda parte de um amplo projeto, em colaboração entre o ICB e o HU - USP, o qual foi aprovado pelos Comitês de Ética do HU - USP (CEP-HU/USP: 752/07), SISNEP CAAE (0031.0.198.019-07), do ICB (PARECER 788/CEP), da Plataforma Brasil (CAAE - 0023.0.019.198-11) e do Clinical Trial (U1111-1140-7773). O procedimento de coleta dos tecidos, descrito no item 3.8, apresentou um grau mínimo de risco ao paciente, e não interferiu nos procedimentos padrões das cirurgias.

\subsection{Critérios de inclusão e exclusão dos diferentes grupos}


Os critérios de inclusão que foram utilizados para todos os pacientes, independentemente dos grupos em que foram inseridos, foram os que não ter recebido tratamentos contra o câncer e/ou antiinflamatórios continuados previamente à seleção inicial, e apresentarem disponibilidade para contribuírem com a pesquisa. Em relação aos critérios de exclusão, os pacientes não poderiam ser portadores de insuficiências hepática e/ou renal, síndrome da imunodeficiência adquirida (SIDA), doenças inflamatórias do intestino e desordens auto-imunes (todas previamente diagnosticadas pelos médicos).

Em relação aos critérios de inclusão para a formação dos grupos, foram considerados grupo controle os pacientes submetidos às cirurgias de hérnia que não apresentaram conteúdo no soro de proteína C-reativa (PCR) superior a $10 \mathrm{mg} / \mathrm{L} \mathrm{e} / \mathrm{ou}$ de albumina inferior à $35 \mathrm{~g} / \mathrm{L}$, pelo fato de estarem correlacionadas à inflamação, de acordo com o escore prognóstico de Glasgow (MCMILLAN, 2008), que é indicador da caquexia associada ao câncer.

Os pacientes com câncer foram divididos em dois grupos, com base nas respostas conferidas na aplicação de dois diferentes questionários, relativos à qualidade de vida e à caquexia (EORTC QLC - 30 e CASCO, respectivamente; anexo $A$ e B), além das medidas antropométricas e bioquímicas.

Foram inseridos no grupo tumor com caquexia $(\mathrm{TcC})$ pacientes que relataram perda de peso não intencional superior a $5 \%$ durante os seis meses prévios (FEARON et al., 2011), além de fadiga, depressão e dor como sintomas (LAIRD et al., 2011). Mesmo tendo Fearon et al. (2011) postulado que a caquexia possa existir sem a presença de inflamação, pacientes que não apresentassem inflamação sistêmica (ou seja, com PCR $\leq 10 \mathrm{mg} / \mathrm{L}$ e/ou albumina $\geq 35 \mathrm{~g} / \mathrm{L}$ ) foram excluídos, uma vez que acreditamos que a inflamação sistêmica seja o critério mais confiável para designá-la.

Em relação ao grupo tumor sem caquexia $(T s C)$, foram neste inseridos pacientes que não relataram perda de peso superior a $5 \%$ de seu peso corporal nos seis meses prévios. O estadiamento tumoral não foi considerado na análise, uma vez que esse parâmetro não apresenta qualquer tipo de relação com a presença de caquexia (MCMILLAN, 2009). 


\subsection{Termo de consentimento}

Após os médicos terem realizado a seleção inicial dos pacientes, estes assinaram um termo de consentimento livre e esclarecido (TCLE, anexo C), em que permitiram que seus dados fossem utilizados no projeto. Posteriormente à assinatura do termo, os pacientes foram submetidos a dois questionários, relativos à qualidade de vida e caquexia (EORTC QLC - 30 e CASCO, respectivamente).

\subsection{Características gerais e parâmetros antropométricos}

O peso, altura e índice de massa corporal (IMC) foram aferidos e, a partir dos questionários, colheu-se a informação sobre a presença ou ausência de perda de peso superior a $5 \%$ no período de seis meses.

\subsection{Coleta de sangue e extração do soro}

Após jejum de 8 horas na noite prévia à cirurgia, aproximadamente $20 \mathrm{~mL}$ de sangue foram colhidos a partir do acesso venoso para anestesia, durante a cirurgia. As amostras de sangue foram então armazenadas em dois tubos e levadas até o laboratório do grupo, onde foram centrifugadas à $12000 \mathrm{~g}$ em uma centrífuga 5430 R, da marca Eppendorf (Eppendorf do Brasil Ltda., São Paulo, S.P.,Brasil) por 10 minutos a $4^{\circ} \mathrm{C}$ para extração da fração sérica. $\mathrm{O}$ soro foi armazenado em um freezer - $80^{\circ} \mathrm{C}$, da marca Thermo Scientific (Thermo Fisher Scientific Inc., Waltham, M.A., Estados Unidos da América) para posteriores análises.

\subsection{Parâmetros bioquímicos analisados no soro dos pacientes}

\subsubsection{Hemoglobina, uréia, glicose e creatinina}

Os parâmetros bioquímicos acima citados foram aferidos pelo HU - USP, através de kits específicos (Hemoglobina), (Uréia CE), (Glicose Liquiform) e (Creatinina), respectivamente, sendo todos da empresa Labtest (Labtest Diagnóstica S.A., Lagoa Santa, M.G., Brasil); de acordo com as instruções do fabricante. As leituras das absorbâncias foram realizadas em um espectrofotômetro Spectra Max 
Plus, da marca Molecular Devices (Molecular Devices L.L.C., Union City, C.A., Estados Unidos da América)

\subsubsection{Proteína C-reativa e albumina}

Os conteúdos de PCR e de albumina foram dosados pelo laboratório RDO, a partir dos kits (CRPLX) e (Albumin Gen. 2), respectivamente, sendo ambos da empresa Roche (Roche Diagnostics, Indianapolis, I.N., Estados Unidos da América); de acordo com as instruções do fabricante.

\subsubsection{Colesterol total}

Para a dosagem do colesterol total as amostras foram incubadas com reagente de trabalho em banho-maria a $37{ }^{\circ} \mathrm{C}$ durante 10 minutos. As absorbâncias foram então determinadas em $500 \mathrm{~nm}$. A determinação de colesterol por este kit baseia-se nas seguintes reações: os ésteres de colesterol são hidrolisados pela colesterol esterase a colesterol livre e ácidos graxos. O colesterol livre é oxidado pela colesterol oxidase gerando peróxido de hidrogênio, o qual reage com fenol e 4aminoantipirina formando uma antipirilquinonimina vermelha. A intensidade da cor vermelha formada na reação final é diretamente proporcional à concentração do colesterol na amostra.

\subsubsection{Lipoproteínas de alta densidade}

A concentração de HDL-colesterol foi determinada através da mistura das amostras com o reagente de trabalho 1 , seguida de incubação a $37^{\circ} \mathrm{C}$ durante 5 minutos. Fez-se então uma primeira leitura das absorbâncias a $600 \mathrm{~nm}$. Posteriormente, o reagente de trabalho 2 foi adicionado às amostras, as quais foram novamente submetidas à incubação a $37{ }^{\circ} \mathrm{C}$ durante 5 minutos. Uma nova leitura das absorbâncias foi feita em espectofotômetro a $600 \mathrm{~nm}$. A seletividade deste método está baseada nas tecnologias de aceleração da reação de colesterol oxidase com o colesterol livre das lipoproteínas não HDL e solubilização seletiva das partículas HDL por ação de um detergente específico. Após a solubilização específica do colesterol HDL, com a ação das enzimas colesterol esterase e 
colesterol oxidase e acoplamento com 4-aminoantipirina e um cromogênio, em reação catalisada pela peroxidase, ocorre o desenvolvimento de uma coloração proporcional à concentração de HDL-colesterol nas amostras.

\subsubsection{Triglicérides}

Para a determinação do triacilglicerol, as amostras, misturadas ao reagente de trabalho, foram incubadas em banho-maria a $37{ }^{\circ} \mathrm{C}$ durante 10 minutos. As absorbâncias foram determinadas em espectofotômetro Spectra Max Plus, da marca Molecular Devices, em $505 \mathrm{~nm}$. Neste ensaio, a lipase de lipoproteína promove a hidrólise dos triacilgliceróis liberando glicerol, que é convertido, pela ação da glicerolquinase, em glicerol-3-fosfato. Este é oxidado a dihidroxiacetona e peróxido de hidrogênio na presença de glicerolfosfato oxidase. Em seguida ocorre uma reação de acoplamento entre peróxido de hidrogênio, 4-aminoantipirina e 4clorofenol, catalisada pela peroxidase, e a intensidade da cor vermelha formada é diretamente proporcional à concentração de triacilglicerol nas amostras.

\subsubsection{Glicerol}

O conteúdo de glicerol foi aferido a partir do kit (Free Glycerol Reagent (número de catálogo F6428), da empresa Sigma (Sigma-Aldricht, Buchs, S.G., Suíça); de acordo com as instruções do fabricante.

O reagente mensura o glicerol endógeno livre, utilizando as mesmas reações acopladas enzimáticas, sem a hidrólise inicial da lípase. O glicerol é fosforilado por adenosina trifosfato (ATP), formando glicerol-1-fosfato (G-1-F) e adenosina difofato, em uma reação catalisada por glicerol quinase. G-1-P é então oxidado por glicerol fosfato oxidase (GFO), gerando dihidroxiacetona fosfato (DAF) e peróxido de hidrogênio (H2O2). A peroxidase cataliza $\mathrm{O}$ acoplamento do $\mathrm{H} 2 \mathrm{O} 2$ com 4aminoantipirina (4-AAP) e sódio $\mathrm{N}$-etil- $\mathrm{N}$-(3-sulfopropil) m-anisidina (ESPA) para produzir um corante de quinoneimina que exibe uma absorbância máxima em 540 nm. O aumento na absorbância em $540 \mathrm{~nm}$ é diretamente proporcional à concentração de glicerol livre da amostra. 


\subsection{7 Ácidos graxos livres}

O conteúdo de ácidos graxos livres foi aferido a partir do kit (HR series NEFAHR (2)), da empresa Wako (Wako Chemicals U.S.A, Richmond, V.A., Estados Unidos da América); de acordo com as instruções do fabricante. As leituras das absorbâncias foram realizadas em um espectrofotômetro Spectra Max Plus, da empresa Molecular Devices.

O princípio do método é baseado na ação das enzimas acil CoA sintetase na presença de ATP e cofatores sobre os ácidos graxos não esterificados (NEFA), originando acil CoA; AMP e Ppi. A acil-CoA é então oxidada dando origem a peróxido de hidrogênio que favorece a reação de N-etil-N-(2hidroxi-3-sulfopropil)-mtosluidina com 4-aminoantipirina, presentes no reagente, dando origem a um complexo que desenvolve coloração púrpura, cuja intensidade medida em comprimento de onda a $550 \mathrm{~nm}$ mantém relação direta com a quantidade de AGNE presente na amostra, sendo considerada a temperatura de reação igual a $37^{\circ} \mathrm{C}$ e os resultados expressos em $\mu \mathrm{mol} / \mathrm{L}$.

\subsubsection{Endotoxina circulante}

A endotoxina no soro foi dosada a partir de um ensaio cromogênico do Lisado de Amebócitos do Limulus ( $L A L$ ), que é um teste quantitativo para endotoxina de bactérias gram-negativa. As soluções necessárias para a realização do experimento, bem como o conteúdo de endotoxinas circulantes foi aferido a partir do kit (Kinetic Chromogenic LAL), da empresa Lonza (Lonza Inc., Allendale, N.J., Estados Unidos da América) (número de catálogo 50-647U); de acordo com as instruções do fabricante.

A endotoxina de bactérias gram-negativas catalisa a ativação de uma proenzima em um lisato de amebócitos limulus (LAL). A taxa inicial da ativação é determinada pela concentração da endotoxina presente. A enzima ativada catalisa a divisão de pNA a partir do substrato incolor Ac-lle-Glu-Ala-Arg-pNA. O pNA liberado é mensurado fotometricamente em absorbância 405-410 nm após o término da reação com o reagente de parada. A correlação entre a absorbância e da concentração da toxina é linear em um intervalo de 0.1-1.0 EU/mL. A concentração 
de endotoxina em uma amostra é calculada a partir de valores de absorbância de soluções contendo conteúdos conhecidos do padrão de endotoxina.

\subsubsection{Quantificação de proteínas específicas}

Para que fossem determinadas as quantidades de TNF- $\alpha$, IL-6 e IFN- $\gamma$ no soro, foram utilizados kits para ELISA específicos destas proteínas (catálogo HSCYTMAG-60SK-06, Millipore). O experimento foi realizado a partir de kits (Multiplex, Luminex) pela empresa Genese (Genese Produtos Diagnósticos Ltda., São Paulo, S.P., Brasil) seguindo as instruções do fabricante. Os reagentes encontrados no kit são proporcionados pela empresa responsável, reagentes como anticorpo monoclonal, padrões de ensaio, anticorpos secundários conjugados com biotina, estreptavidina conjugada com a proteína florescente, tampões e lavagem e a placa de 96 poços.

Resumidamente, 96-poços com filtro foram pré-umedecidos com tampão de lavagem e a solução foi aspirada dos poços usando uma sucção à vácuo (Millipore Corporation, Billerica, M.A., Estados Unidos da América). Micro-esferas revestidas com anticorpos monoclonais contra os 5 alvos diferentes analisados foram adicionadas aos poços. Amostras e padrões (variando de 0,13 a $2.000 \mathrm{pg} / \mathrm{ml}$ para cada análise) foram pipetados nos poços e incubados durante a noite a $4{ }^{\circ} \mathrm{C}$. Os poços foram lavados e aspirados e uma mistura de anticorpos biotinilados secundários foi adicionada. Após a incubação por 1 hora, estreptavidina conjugada com a proteína fluorescente, R-ficoeritrina (estreptavidina-RPE) foi adicionada às microesferas e incubadas por 30 minutos. Após a lavagem para remoção dos reagentes não aderidos, foi adicionada aos poços com as microesferas (mínimo de 100 por análise) uma solução tampão sheath fluid (Luminex®, MiraiBio, Alameda, C.A., Estados Unidos da América) para serem analisadas no analisador de microesferas (Luminex 100 ${ }^{\mathrm{TM}}$, Luminex ${ }^{\circledR}$, MiraiBio, Alameda, CA, Estados Unidos da América). As concentrações das amostras desconhecidas (antígenos nas amostras de FG) foram estimadas a partir da curva padrão, utilizando o Bio-Plex Manager Software (Bio-Rad Laboratories, Hercules, CA, Estados Unidos da América). Os níveis das citocinas foram expressos como quantidade total por sítio (pg / sítio).

A concentração das citocinas avaliadas no soro foi expressamente de acordo com o $\mathrm{mL}$ de soro, no entanto a concentração de citocinas no tecido foi relativizado 
pela proteína total do tecido. As concentrações de todas as proteínas foram determinadas em duplicata.

\subsection{Coleta e estoque do tecido adiposo}

Aproximadamente um grama (g) de tecido adiposo branco (TAB) subcutâneo de cada paciente foi retirado pelos médicos durante a intervenção cirúrgica, na qual foi realizada uma incisão a $1 \mathrm{~cm}$ à direita e acima da cicatriz umbilical. As amostras do tecido acima citado foram armazenadas em tubos contendo: $1 \mathrm{~mL}$ do reagente $\left(T R / z o I^{\circledR}\right)$, da marca Invitrogen (Invitrogen do Brasil Ltda., São Paulo, S.P., Brasil) para posterior extração de ácido ribonucléico (RNA) total (cerca de $300 \mathrm{mg}$ de tecido); e em tubo seco para posterior extração de proteínas totais (cerca de $300 \mathrm{mg}$ de tecido). Para análises posteriores, as amostra foram armazenados em freezer $80^{\circ} \mathrm{C}$.

\subsection{Medida da expressão gênica por PCR tempo real}

O RNA total do tecido foi extraído a partir de alíquotas de $300 \mathrm{mg}$ de tecido através da extração com reagente Trizol $^{\circledR}$. As amostras foram homogeneizadas em aparelho (Polytron) (PT 3100) e incubadas por 10 minutos a temperatura ambiente. As amostras foram precipitadas com $200 \mu \mathrm{L}$ de clorofórmio e centrifugadas por 15 minutos a $12.000 \times \mathrm{g}\left(4{ }^{\circ} \mathrm{C}\right)$ para a obtenção do RNA total (fase superior) que foi precipitada com $500 \mu \mathrm{L}$ de álcool isopropílico e incubada por 10 minutos a temperatura ambiente. Os pellets foram lavados com etanol $95 \%$ e as amostras foram centrifugadas por 5 minutos a $7.500 \times \mathrm{g}$, a $4{ }^{\circ} \mathrm{C}$. O álcool foi removido e os pellets secos a temperatura ambiente por 15 minutos. As amostras foram então solubilizadas com $20 \mu \mathrm{L}$ de água DEPC inativa. A concentração de RNA foi determinada por espectofotômetro Biomate 3, da empresa ThermoScientific (ThermoScientific, Austin, Texas, Estados Unidos da América). A síntese de DNA complementar foi realizada a partir de $2 \mu \mathrm{g}$ de RNA total e um mix de reagentes (High Capacity cDNA Reverse Transcription Kits, Invitrogen, Foster City, C.A., Estados Unidos da América), composto por $2 \mu \mathrm{L}$ de RT Random Primer; 0,8 $\mu \mathrm{L}$ de dNTP Mix (100 mM); $2 \mu \mathrm{L}$ de RT Buffer e $1 \mu \mathrm{L}$ da enzima transcriptase reversa MultiScribe $^{\mathrm{TM}}(50 \mathrm{U} / \mu \mathrm{L})$. Em um volume final de $20 \mu \mathrm{L}, 2 \mu \mathrm{L}$ de DNA complementar 
foram misturados com 2x SYBR Green PCR master mix (Applied Biosystems, Foster City, C.A., Estados Unidos) e sequências específicas de oligonucleotídios (Invitrogen).

Os oligonucleotídeos foram desenhados a partir de sequências disponíveis no GenBank (http://www.ncbi.nlm.nih.gov/genbank), com o auxílio dos sites Spidey (http://www.ncbi.nlm.nih.gov/spidey/spideyweb.cgi) e 3 Primer 3 (http://biotools.umassmed.edu/bioapps/primer3_www.cgi). Após a definição das sequências, a especificidade pôde ser aferida através do site BLAST (http://blast.ncbi.nlm.nih.gov/Blast.cgi). A análise de PCR tempo real foi usada para determinação da expressão gênica de TLR-4, MyD88, TRAF-6 e p65 no tecido adiposo subcutâneo de pacientes dos grupos controle, portador de tumor com peso estável e portador de tumor com caquexia; sendo o gene $18 \mathrm{~S}$ utilizado como gene de referência (controle). As sequências dos oligonucleotídeos utilizados para amplificação dos genes de interesse estão ilustradas na tabela 2.

Os níveis de RNA mensageiro foram determinados a partir do método comparativo Ct, descrito por Livak e Schmittgen (2001). Para cada amostra, um valor $\Delta \mathrm{Ct}$ foi obtido, subtraindo-se o valor da média da duplicata do gene $18 \mathrm{~S}$ da média da duplicata do gene de interesse. Um valor $\Delta \mathrm{Ct}$, correspondente à media das amostras do grupo controle, foi então subtraído de cada amostra (dos três diferentes grupos), obtendo-se um valor $-\Delta \Delta \mathrm{Ct}$; sendo a expressão gênica avaliada a partir de um valor $2^{-\Delta \Delta C t}$. 
Tabela 2 - Primers utilizados para a amplificação dos genes de interesse, a partir das sequências disponíveis no GenBank

\begin{tabular}{|c|c|c|}
\hline Gene & Sense (5' - 3') & Antisense (5' - 3') \\
\hline $\begin{array}{l}18 S \\
\left(H Q \_387008\right)\end{array}$ & CCTGCGGCTTAATTTGACTC & ATGCCAGAGTCTCGTTCGTT \\
\hline $\begin{array}{l}\text { TLR-4 } \\
\text { (NM_0032663) }\end{array}$ & TAAGGTTGCCGCTTTCACTT & ATCATCCTGGCATCATCCTC \\
\hline $\begin{array}{l}\text { MyD88 } \\
(\text { NM_0024684) }\end{array}$ & CCGCAGGAGAAAGAGGAAG & CGCACGTTCAAGAACAGAGA \\
\hline $\begin{array}{l}\text { TRAF-6 } \\
(\text { NM_0046203) }\end{array}$ & TGCCATGAAAAGATGCAGAG & CCGGATTTGATGGTCTTGTC \\
\hline $\begin{array}{l}\text { p65 } \\
\text { (NM_001243985) }\end{array}$ & CCTGGAGCAGGCTATCAGTC & ATGGGATGAGAAAGGGACAGG \\
\hline
\end{tabular}

\subsection{Extração de proteínas e quantificação de proteínas totais}

Inicialmente, $300 \mathrm{mg}$ de tecido adiposo subcutâneo foram homogeneizados em homogeneizador Polytron (PT 3100) em $1 \mathrm{~mL}$ de tampão de extração (Trizma base $100 \mathrm{mM} \mathrm{pH} \mathrm{7,5,} \mathrm{EDTA} 10 \mathrm{mM}$, SDS $10 \%$, fluoreto de sódio $100 \mathrm{mM}$, pirofosfato de sódio $10 \mathrm{mM}$, ortovanadato de sódio $10 \mathrm{mM}$ ). O tampão foi preparado no dia do experimento e aquecido em banho-maria fervente. O homogenato resultante foi transferido para tubos eppendorfs e centrifugado (40 minutos, 12.000 rpm, a $4{ }^{\circ} \mathrm{C}$ ). Em seguida, a fração líquida foi cuidadosamente coletada evitando-se a contaminação com a fração lipídica na fase superior do tubo. As amostras foram armazenadas em freezer -80, para analises posteriores.

O conteúdo das proteínas totais de cada amostra foi avaliado de acordo com Bradford (1976), tendo sido utilizado o kit comercial (Quick Start ${ }^{\mathrm{TM}}$ Bradford Protein Assay), da marca Bio-Rad (Bio-Rad, Hercules, C.A., Estados Unidos da América).

\subsection{Análise estatística}

Os parâmetros antropométricos e bioquímicos, bem como as análises de expressão gênica e protéica estão expressos em média \pm erro. Os dados dos parâmetros antropométricos e bioquímicos apresentaram distribuição Gaussiana, e 
por esta razão a significância foi determinada por análise paramétrica (teste ANOVA one-way seguido por pós-teste de Tuckey). Os dados das análises de expressão gênica e protéica não apresentaram distribuição Gaussiana, e por isso a significância foi determinada por análise não-paramétrica (teste de Kruskal-Wallis seguido de um pós-teste de Dunn). Foi considerada diferença estatística $p<0,05$. A análise estatística foi realizada pelo software Graphpad Prism, versão 5.0. 


\section{RESULTADOS}

\subsection{Avaliação dos parâmetros antropométricos}

Na tabela 3 estão descritos os valores das características antropométricas dos seguintes parâmetros: peso, altura e IMC. Não foi verificada qualquer diferença estatística entre os grupos.

Tabela 3 - Características gerais e parâmetros antropométricos dos pacientes



Nota: Resultados expressos como média \pm EPM.

Abreviaturas: M: masculino; F: feminino.

\subsection{Avaliação dos parâmetros bioquímicos}

Na Tabela 4 estão descritos os valores da concentração sérica dos seguintes parâmetros bioquímicos: hemoglobina, uréia, creatinina, glicose, proteína C-reativa, albumina, glicerol, colesterol total, glicerol, ácidos graxos livres, endotoxina, triacilglicerol e colesterol HDL.

Foi verificado um aumento de 2,03 vezes na concentração sérica de uréia no grupo TcC ( $p=0,008$ vs. TsC), e a concentração de creatinina encontrou-se aumentada 1,29 vezes no grupo controle ( $p=0,018$ vs. TsC). A concentração de proteína C-reativa estava muito aumentada no grupo TcC (33,84 vezes vs. controle e 12,76 vezes vs. TsC, sendo $\mathrm{p}<0,0001$ para ambos os grupos), e a albumina diminuída neste mesmo grupo (1,45 vezes vs. controle e 1,42 vezes vs. TsC, sendo $p<0,0001$ para ambos grupos). Ao analisar o perfil lipídico dos pacientes, verificouse no grupo TcC que, em relação ao grupo controle, o nível de glicerol estava aumentado 2 vezes ( $p=0,003)$, o de triacilglicerol 1,22 vezes ( $p=0,033$ ) e o de colesterol total 1,23 vezes $(p=0,013$ ). Além disso, foi verificado no grupo TcC um 
conteúdo aumentado de ácidos graxos livres (1,13 vs. controle e 1,14 vs. TsC, sendo $p=0,026$ para ambos os grupos); além de uma quantidade reduzida de colesterol HDL (1,58 vs. controle e 1,61 vs. TsC, sendo $p=0,0003)$.

Ainda na tabela 4, pôde-se verificar que não houve alterações nas concentrações séricas de hemoglobina $(p=0,460)$, glicose $(p=0,840)$ e endotoxina $(p=0,522)$ entre os grupos.

Tabela 4 - Características bioquímicas dos pacientes por grupo

\begin{tabular}{|c|c|c|c|c|c|c|c|c|c|}
\hline \multirow{3}{*}{$\begin{array}{l}\text { Parâmetro } \\
\text { HEMOGLOBINA (mg/dl) }\end{array}$} & \multicolumn{3}{|c|}{ CONTROLE } & \multicolumn{5}{|c|}{ TUMOR } & \multirow{3}{*}{$\begin{array}{c}p \\
0,460\end{array}$} \\
\hline & & & & \multicolumn{3}{|c|}{ Sem caquexia } & \multicolumn{2}{|c|}{ Com caquexia } & \\
\hline & 14,64 & \pm & 0,46 & 14,36 & \pm & 0,86 & 13,23 & $\pm \quad 1,70$ & \\
\hline UREIA (mg/dl) & 32,54 & \pm & 2,89 & 23,14 & \pm & 1,82 & $47^{b}$ & $\pm 10,22$ & 0,008 \\
\hline CREATININA (mg/dl) & 0,95 & \pm & 0,06 & $0.74^{\mathrm{a}}$ & \pm & 0,04 & 0,77 & $\pm \quad 0,06$ & 0,018 \\
\hline GLICOSE (mg/dl) & 96,62 & \pm & 3,94 & 96,00 & \pm & 1,68 & 100,67 & $\pm \quad 3,33$ & 0,840 \\
\hline PROTEÍNA C-REATIVA (mg/l) & 0,89 & \pm & 0,17 & 2,36 & \pm & 0,54 & $30,15^{a, b}$ & $\pm \quad 2,35$ & $<0,0001$ \\
\hline ALBUMINA (g/l) & 41,27 & \pm & 1,15 & 40,50 & \pm & 1,04 & $28,43^{a, b}$ & $\pm 1,45$ & $<0,0001$ \\
\hline GLICEROL $(\mathrm{mg} / \mathrm{ml})$ & 0,056 & \pm & 0,008 & 0,079 & \pm & 0,015 & $0,113^{\mathrm{a}}$ & $\pm 0,013$ & 0,003 \\
\hline COLESTEROL TOTAL (mg/dl) & 164,37 & \pm & 8,54 & 170,42 & \pm & 8,36 & $201,69^{a}$ & $\pm 9,38$ & 0,013 \\
\hline ÁCIDOS GRAXOS LIVRES (mEq/l) & 0,997 & \pm & 0,020 & 0,983 & \pm & 0,019 & $1,123^{a, b}$ & $\pm 0,067$ & 0,026 \\
\hline ENDOTOXINA (EU/mI) & 0,841 & \pm & 0,121 & 0,985 & \pm & 0,170 & 1,081 & $\pm 0,159$ & 0,522 \\
\hline TRIACILGLICEROL $(\mathrm{mg} / \mathrm{dl})$ & 127,93 & \pm & 6,00 & 132,81 & \pm & 10,60 & $155,54^{a}$ & $\pm \quad 5,39$ & 0,033 \\
\hline Colesterol HDL (mg/dl) & 58,81 & \pm & 3,63 & 59,94 & \pm & 4,07 & $37,24^{a, b}$ & $\pm \quad 4,07$ & 0,0003 \\
\hline
\end{tabular}

Nota: Resultados expressos como média \pm EPM. Abreviatura: HDL: lipoproteína de alta densidade.

\subsection{Avaliação da expressão de citocinas no soro}

Os resultados das análises das citocinas TNF- $\alpha$, IL-6 e IFN- $\gamma$ no soro estão demonstrados na Figura 2. O ensaio de concentração de citocinas no soro foi realizado com o intuito de se verificar-se a existência de inflamação sistêmica nos pacientes do grupo TcC. O conteúdo de TNF- $\alpha$ encontrou-se 2,22 vezes no grupo TcC ( $p=0,0416$ vs. controle) (figura 2-A), assim como a IL-6, aumentada 5,32 vezes no mesmo grupo ( $p=0,0029$ vs. controle) (figura 3-B). Já em relação ao IFN-y, não houve qualquer diferença significativa entre os grupos $(p=0,6958)$ (figura 2-C). 
Figura 2 - Expressão das citocinas TNF- $\alpha$, IL-6 e IFN-y no soro. (A) a expressão de TNF- $\alpha$, (B) expressão de IL-6 e (C) expressão de IFN-Y.

A

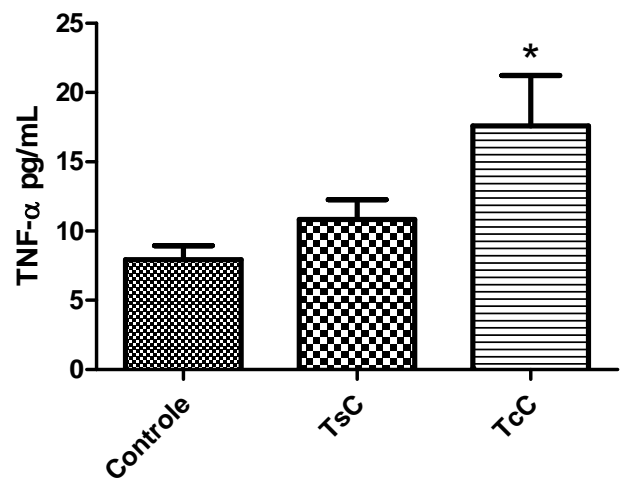

\begin{tabular}{c|c|c}
\hline GRUPOS & \multicolumn{2}{|c}{ TNF- $\alpha$} \\
\hline & Média & e.p.m \\
Controle & 7,919 & 1,024 \\
TsC & 10,855 & 1,407 \\
TcC & 17,586 & 3,646 \\
\hline
\end{tabular}

B

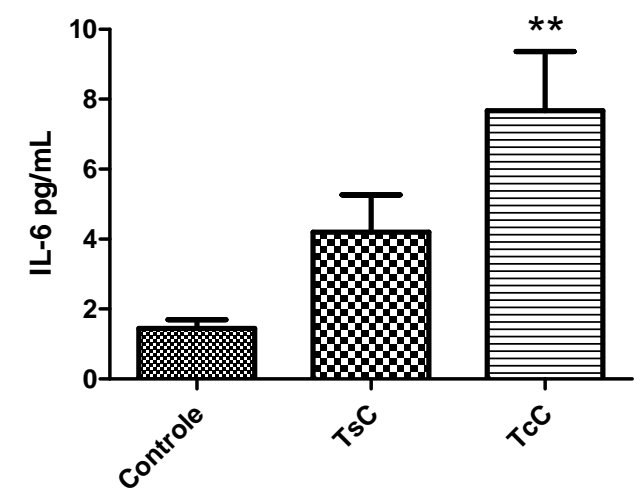

\begin{tabular}{c|c|c}
\hline GRUPOS & \multicolumn{2}{|c}{ IL-6 } \\
\hline & Média & e.p.m \\
Controle & 1,443 & 0,251 \\
TsC & 4,194 & 1,065 \\
TcC & 7,670 & 1,690 \\
\hline
\end{tabular}

C

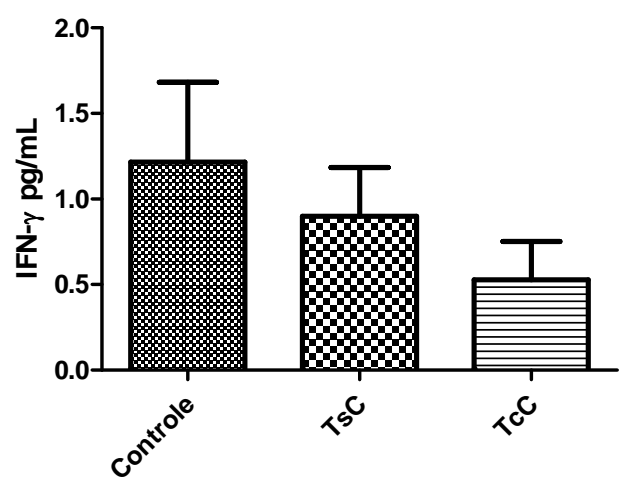

\begin{tabular}{c|c|c}
\hline GRUPOS & \multicolumn{2}{|c}{ IFN- $\gamma$} \\
\hline & Média & e.p.m \\
Controle & 0,875 & 0,165 \\
TsC & 2,189 & 0,644 \\
TcC & 5,913 & 2,056 \\
\hline
\end{tabular}

Nota: Os valores foram expressos em média \pm EPM

Abreviaturas: TsC: tumor sem caquexia; TcC: tumor com caquexia

Para a análise estatística foi utilizado Kruskal-Wallis seguido pelo pós teste de Dunn: * $\mathrm{p}<0,05 \mathrm{e}$ ${ }^{* *} \mathrm{p}<0,01$ em relação ao controle. 


\subsection{Avaliação da expressão de citocinas no tecido adiposo}

Os resultados das análises das citocinas TNF- $\alpha$, IL-6 e IFN- $\gamma$ no TAB estão demonstrados na Figura 3. A concentração de TNF- $\alpha$ encontrou-se aumentada 3,90 vezes no grupo TcC ( $p=0,0066$ vs. controle) (figura 3-A), assim como o de IL-6, aumentado 9,79 vezes no mesmo grupo ( $p=0,003$ vs. controle) (figura 3-B). Já em relação ao IFN- $\gamma$, não houve qualquer diferença significativa entre os grupos ( $p=$ $0,1653$ ) (figura $3-C)$.

Figura 3 - Expressão das citocinas TNF- $\alpha$, IL-6 e IFN-y no tecido. (A) a expressão de TNF-a, (B) expressão de IL-6 e (C) expressão de IFN- $\gamma$.

A

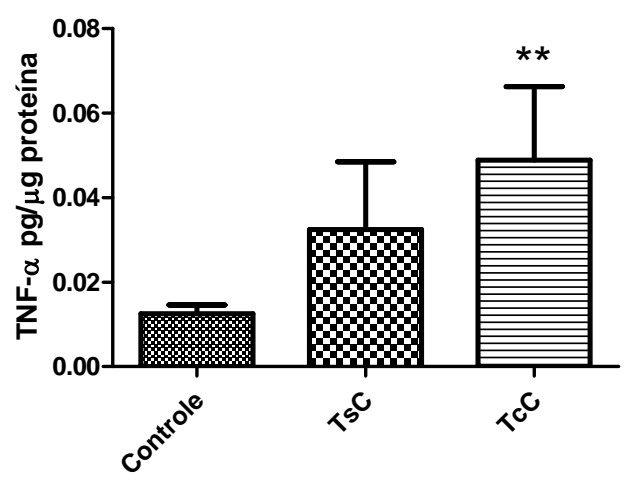

\begin{tabular}{c|c|c}
\hline GRUPOS & \multicolumn{2}{|c}{ TNF- $\alpha$} \\
\hline & Média & e.p.m \\
Controle & 0,013 & 0,002 \\
TsC & 0,032 & 0,016 \\
TcC & 0,049 & 0,017 \\
\hline
\end{tabular}

B



\begin{tabular}{c|c|c}
\hline GRUPOS & \multicolumn{2}{|c}{ IL-6 } \\
\hline & Média & e.p.m \\
Controle & 0,063 & 0,010 \\
TsC & 0,147 & 0,035 \\
TcC & 0,614 & 0,219 \\
\hline
\end{tabular}


C

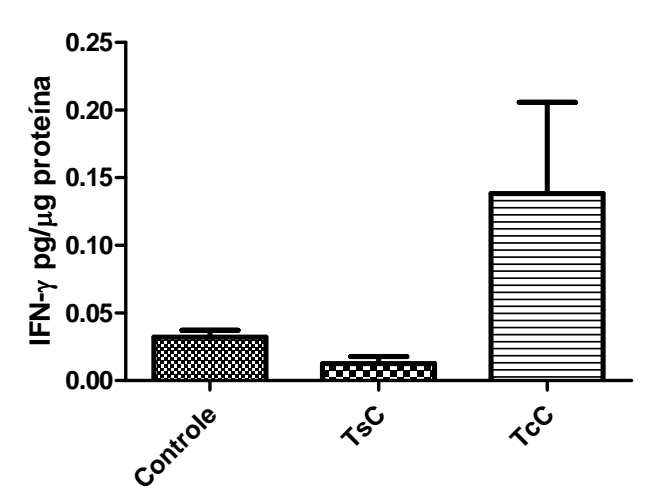

\begin{tabular}{c|c|c}
\hline GRUPOS & \multicolumn{2}{|c}{ IFN-y } \\
\hline & Média & e.p.m \\
Controle & 0,032 & 0,005 \\
TsC & 0,013 & 0,005 \\
TcC & 0,138 & 0,068 \\
\hline
\end{tabular}

Nota: Os Valores foram expressos em média \pm EPM

Abreviaturas: TsC: tumor sem caquexia; TcC: tumor com Caquexia

Para a análise estatística foi utilizado Kruskal-Wallis seguido pelo pós teste de Dunn: ${ }^{* *} \mathrm{p}<0,01 \mathrm{em}$ relação ao controle.

\subsection{Expressão gênica das proteínas de interesse}

Os resultados das análises da expressão gênica do TLR-4, MyD88, TRAF-6 e p65 no tecido adiposo subcutâneo estão demonstrados na Figura 4. Verificou-se que a expressão gênica de TLR-4 estava aumentada 3,27 vezes no grupo TcC ( $p=$ 0,0155 vs. controle) (figura 4-A). Para examinar se o aumento no conteúdo do RNAm de TLR-4 seria acompanhado por uma modificação nas transcrição dos demais RNAm que compõem a via, examinou-se a expressão gênica de MyD88 e TRAF-6 (respectivamente a primeira e a última proteínas da via). O conteúdo de RNAm do MyD88 mostrou-se aumentado no grupo TcC (3,86 vs. controle e 3,44 vezes vs. TsC, sendo $p=0,0143$ para ambos os grupos) (figura 4-B), assim como o de TRAF-6 (figura 4-C) (6,01 vezes vs. controle, sendo $p=0,0339)$. A participação da via do NFKB na inflamação do TAB foi investigada através da análise da expressão gênica da subunidade p65 deste fator de transcrição, que mostrou-se 6,76 vezes aumentada no grupo TcC em comparação ao grupo controle $(p=0,0353)$ (figura 4-D). 
Figura 4 - Expressão gênica das proteínas TLR-4, MyD88, TRAF-6 e p65. (A) expressão gênica de TLR-4, (B) expressão gênica de MyD88, (C) expressão gênica de TRAF-6 e (D) expressão gênica de p65.

A

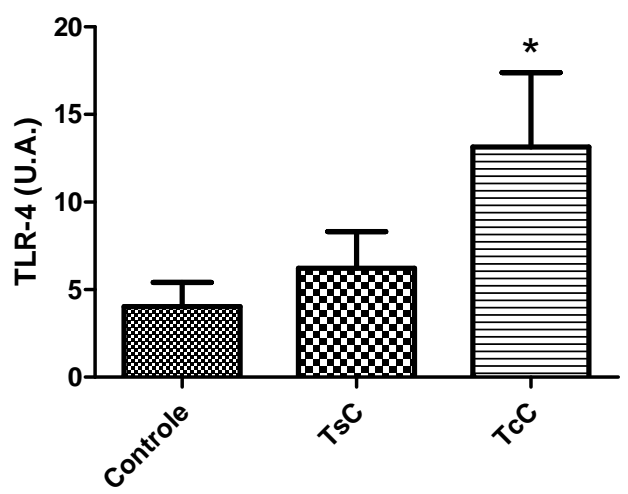

\begin{tabular}{c|c|c}
\hline GRUPOS & \multicolumn{2}{|c}{ TLR-4 } \\
\hline & Média & e.p.m \\
Controle & 4,020 & 1,382 \\
TsC & 6,222 & 2,092 \\
TcC & 13,146 & 4,244 \\
\hline
\end{tabular}

B



\begin{tabular}{c|c|c}
\hline GRUPOS & \multicolumn{2}{|c}{ MyD88 } \\
\hline & Média & e.p.m \\
Controle & 5,458 & 1,762 \\
TsC & 6,120 & 2,960 \\
TcC & 21,044 & 5,150 \\
\hline
\end{tabular}

C

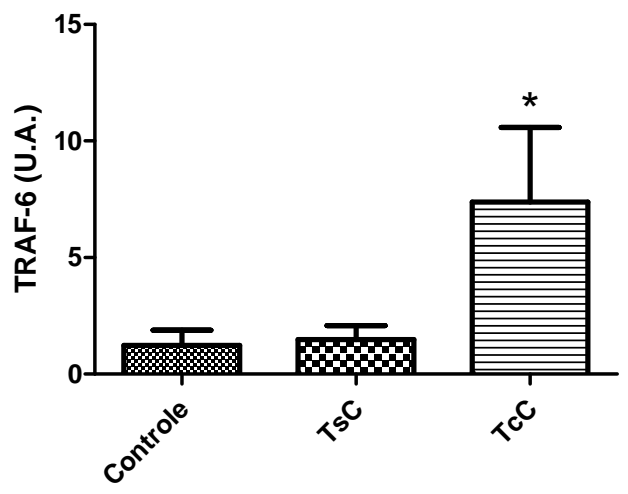

\begin{tabular}{c|c|r}
\hline GRUPOS & \multicolumn{2}{|c}{ TRAF-6 } \\
\hline & Média & e.p.m \\
Controle & 1,228 & 0,656 \\
TsC & 1,477 & 0,608 \\
TcC & 7,379 & 3,199 \\
\hline
\end{tabular}


D

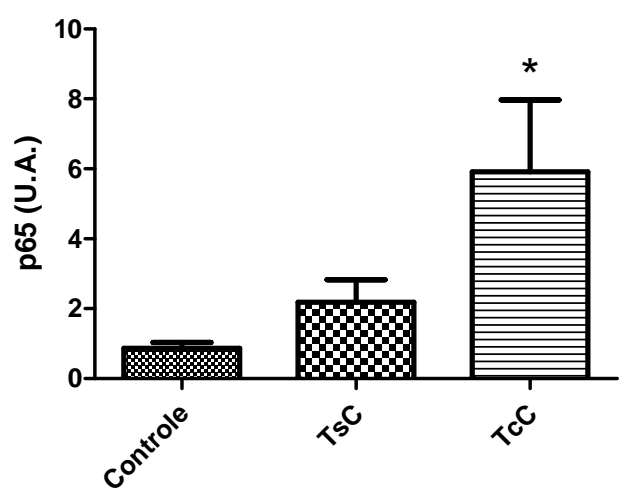

\begin{tabular}{c|c|c}
\hline GRUPOS & \multicolumn{2}{|c}{ P65 } \\
\hline & Média & e.p.m \\
Controle & 0,875 & 0,165 \\
TsC & 2,189 & 0,644 \\
TcC & 5,913 & 2,056 \\
\hline
\end{tabular}

Nota: Os Valores foram expressos em média \pm EPM e normalizado pelo gene controle $18 \mathrm{~S}$. Abreviatura: TsC: tumor sem caquexia; TcC: tumor com Caquexia; U.A.: unidades arbitrarias.

Para a análise estatística foi utilizado ANOVA one-way seguido pelo pós teste de Tukey: * $p<0,05 \mathrm{em}$ relação ao controle; \# p<0,05 em relação ao TsC. 


\section{DISCUSSÃO}

A caquexia é definida como uma síndrome multifatorial caracterizada por perda de massa muscular e tecido adiposo, que afeta cerca de $50 \%$ dos pacientes com câncer e encontra-se presente em mais de dois terços de indivíduos com câncer avançado (ARGILÉS; ALVAREZ; LÓPEZ-SORIANO, 1997; FEARON; MOSES, 2002). Embora descrita há mais de dois mil anos, até os dias atuais sua etiologia é desconhecida (VAN HAEHLING et al., 2002).

Aparentemente fatores secretados pelo tumor contribuem para a mobilização tanto de ácidos graxos, quanto de proteínas (TISDALE, 1999). No entanto, é cada vez mais aceito que, na caquexia, o aumento na produção de citocinas próinflamatórias pelo hospedeiro em decorrência da presença do tumor tem papel fundamental na etiologia da doença (FEARON; MOSES, 2002; LUNDHOLM et al., 2004); sendo o TNF- $\alpha$, a IL-6 e o IFN- $\gamma$ capazes de induzir, isoladamente, diversos dos sintomas relacionados à síndrome (ARGILÉS et al., 2003). Em estudos prévios do nosso grupo, Silvério (2011), verificou que pacientes com câncer e caquexia apresentaram um aumento na concentração de TNF- $\alpha$ no plasma de aproximadamente sete vezes em comparação a indivíduos não caquéticos, e Batista Junior et al. (2013), que as concentrações elevadas não só de TNF-a, mas também de IL-6, estavam presentes no plasma de pacientes com câncer e caquexia $(6,53$ vezes em comparação ao grupo TsC e 12,41 vezes em comparação ao grupo controle).

A inflamação sistêmica é uma característica marcante da caquexia, e é sabido que a via sinalizadora do TLR-4 dependente do MyD88 apresenta evidente participação na modulação da inflamação (TSUKUMO et al., 2007), sendo o tecido adiposo, em particular o subcutâneo, o primeiro a responder à inflamação sistêmica. Ao mesmo tempo em que é afetado pela caquexia, este tecido contribui sobremaneira para sua evolução, pois secreta ativamente uma pletora de fatores inflamatórios que podem contribuir tanto para a inflamação local, quanto sistêmica. Sendo assim, aferir o papel desta via na inflamação do tecido adiposo torna-se importante na tentativa de compreensão dos mecanismos envolvidos na evolução da caquexia. Foi, assim, nosso interesse, após comprovação prévia de que o tecido adiposo de pacientes caquéticos estava inflamado (BATISTA JUNIOR et al., 2013), averiguar se a via do TLR-4 apresentava relevância no processo. 
Os dados obtidos neste estudo em relação ao conteúdo de TNF- $\alpha$ e IL-6 no soro dos pacientes com caquexia corroboram os encontrados por estudos prévios e pela literatura, demonstrando a ocorrência de inflamação crônica e sistêmica nestes pacientes.

Fearon et al. (1988) apontaram o conteúdo de albumina, diminuído no soro de pacientes caquéticos em comparação a indivíduos saudáveis, como um marcador proposto para o diagnóstico de caquexia, e Ridker et al. (2000) citaram a proteína Creativa ( $P C R)$, uma proteína de fase aguda, como outro marcador útil no diagnóstico da síndrome. Em situações em que há inflamação, o conteúdo de PCR no soro encontra-se aumentado (BAUMANN; GAULDIE, 1994). Segundo o valor prognóstico de Glasgow, pacientes com conteúdo de PCR superior a $10 \mathrm{mg} / \mathrm{L}$ e albumina inferior a $35 \mathrm{~g} / \mathrm{L}$ no soro apresentam elevado grau de inflamação (MCMILLAN, 2008). Os resultados obtidos neste trabalho, tanto em relação à $\mathrm{PCR}$ quanto à albumina, indicam que os pacientes caquéticos, de fato, encontravam-se sob inflamação crônica sistêmica.

Tanto em modelos experimentais (BYERLEY et al., 2010), quanto em estudos longitudinais com humanos (FOULADIUN et al., 2005) foi verificado que a perda de gordura precede a perda de massa magra. Bing (2011) relatou que o tecido adiposo subcutâneo é o primeiro tecido a responder à inflamação, e Murphy et al. (2010), uma perda acelerada de tecido adiposo em pacientes caquéticos nos sete meses prévios ao óbito. Estes dados sugerem que, além de um evento precoce na vigência da caquexia, a perda de tecido adiposo poderia servir como um preditor de sobrevivência (MURPHY et al., 2010). Apesar disso, diferentes depósitos de TAB não respondem da mesma forma à caquexia (BATISTA JUNIOR et al., 2013).

A perda de tecido adiposo pode ocorrer tanto devido a um aumento na lipólise (AGUSTSSON et al., 2007), quanto por uma diminuição na lipogênese (ARGILÉS; ALVAREZ; LÓPEZ-SORIANO, 1997). Além do tecido adiposo, os demais tecidos periféricos também são incapazes de captar AGLs e TAG do sangue (ARGILÉS; ALVAREZ; LÓPEZ-SORIANO, 1997), o que contribui para alterações no perfil lipídico sérico dos pacientes caquéticos em relação a pacientes saudáveis, tão acentuadas que foram preconizadas como marcadores para diagnóstico inicial de câncer (ARGILÉS; ALVAREZ; LÓPEZ-SORIANO, 1997). Os pacientes do grupo TcC apresentaram conteúdo aumentado de triacilglicerol e colesterol total, além de redução na fração HDL, confirmando o descrito pela literatura. Evans e Williamson 
(1988) sugeriram que este quadro ocorre devido a uma redução da atividade da enzima lipase lipoprotéica (LPL), responsável pela remoção de TAG do soro para os tecidos periféricos, e Mulligan e Tisdale (1991), que a maior lipogênese hepática estaria relacionada a um maior conteúdo de lipídios no sangue.

Apesar da diminuição da lipogênese estar associada à perda do tecido adiposo, Agustsson et al. (2007) e Rydén et al. (2008) apontaram a lipólise aumentada como fator determinante para que este efeito ocorra, baseada inicialmente no aumento da concentração de ácido graxos e glicerol no sangue de pacientes caquéticos. Neste estudo, níveis elevados tanto de glicerol quanto de ácidos graxos livres foram verificados nos pacientes do grupo TcC, indicando uma maior lipólise (figura 4). Tanto as enzimas LHS e ATGL, quanto as citocinas TNF-a e IL-6 estão implicadas neste processo (BING, 2011).

O conteúdo aumentado de AGLs no sangue, resultado desta maior lipólise, acarreta em um quadro de resistência à insulina (GAO et al., 2004), um sintoma comum em indivíduos caquéticos (TAYEK, 1992). Os pacientes do grupo TcC apresentaram, neste estudo, taxa de glicose no sangue superior a $100 \mathrm{mg} / \mathrm{dL}$, indicando a presença de um quadro pré-diabético (AMERICAN DIABETES ASSOCIATION, 2012).

O tecido adiposo, além de apresentar funções de armazenamento, isolamento e proteção mecânica, é também um órgão endócrino, capaz de secretar ativamente vários hormônios, proteínas e citocinas, que por sua vez regulam o metabolismo lipídico e a homeostasia vascular (POND, 1999). Entre tais fatores, destacam-se o TNF-a e a IL-6, além dos hormônios leptina, adiponectina e resistina (YANG et al., 2002).

Segundo Ahima (2006), embora seja constituído principalmente por adipócitos, o TAB contém outros componentes, como matriz de tecido conjuntivo, fibras nervosas, nódulos linfáticos, pré-adipócitos, fibroblastos, estroma vascular, leucócitos e macrófagos. Lumeng, Deyoung e Saltiel (2007) apontaram os macrófagos como sendo uma importante fonte de citocinas pró-inflamatórias, como o TNF- $\alpha$, capaz per se, de induzir a expressão de uma gama de citocinas próinflamatórias; e fatores quimioatraentes de macrófagos pelos adipócitos.

A presença de um infiltrado de macrófagos no TAB de ratos caquéticos foi verificada por nosso grupo (MACHADO; COSTA ROSA; SEELAENDER, 2004), e neste mesmo estudo, os autores apontaram uma relação direta entre a quantidade 
de macrófagos e a produção de TNF-a e PGE2, indicando inflamação do tecido adiposo. Seelaender e Batista Junior (2010) verificaram, no tecido subcutâneo de pacientes com caquexia associada ao câncer, expansão do espaço estromal, com a presença de um infiltrado imunitário inflamatório, que supostamente seria composto por macrófagos. Optamos por estudar o TAB subcutâneo, pois, além de responder prontamente à inflamação, é um tecido que, por estar próximo da superfície corporal, apresenta maior facilidade de coleta por parte dos médicos, sem necessidade, inclusive, de cirurgia, pois a obtenção pode ser por biópsia. Além disso, Batista Junior et al. (2013) conferem ao tecido TAB subcutâneo a responsabilidade de principal contribuinte para a produção de fatores pró-inflamatórios que acarretam em inflamação local e possivelmente, a inflamação sistêmica. $O$ mesmo não foi verificado no $T A B$ visceral (principal contribuinte para a inflamação na obesidade (DEIULIIS et al., 2011), confirmando que, em humanos, diferentes depósitos de TAB apresentam comportamentos distintos na caquexia, assim como verificado em ratos caquéticos (BERTEVELLO; SEELAENDER, 2001).

Além do conteúdo das citocinas TNF- $\alpha$ e IL-6 no TAB subcutâneo, a concentração de IFN- $\gamma$, citocina que também está relacionada ao desenvolvimento da caquexia (DODSON et al., 2011), foi igualmente aferida. Embora o parâmetro não tenha apresentado diferença significativa no grupo TcC, aqueles referentes ao TNFa e IL-6 apresentaram-se significativamente elevados nestes pacientes (figura 3), demonstrando que o TAB estava localmente inflamado.

Barnes e Karin (1997) apontaram a ativação da via do NFkB como fundamental para a modulação da inflamação, e Baker, Hayden e Ghosh (2011) afirmaram que esta via desempenha um importante papel no desencadeamento e coordenação da resposta imunitária, incluindo a regulação da indução de IL-6 e TNF- $\alpha$. A ativação desta via está aumentada no TAB de indivíduos obesos (MEDZHITOV; JANEWAY, 1998) e portadores de diabetes do tipo II (CREELY et al., 2007), apresentando um importante papel na liberação de citocinas próinflamatórias. Kawai e Akira (2007) postularam que receptores Toll-like são capazes de regulá-la, e Takeda e Akira (2005), mais especificamente, que a via do TLR-4 dependente do MyD88 ativa a via do NFkB.

$\mathrm{Na}$ caquexia, como já verificado, ocorre um aumento na taxa de lipólise, com conseqüente aumento na liberação de AGLs. Hussey et al. (2012) apontaram a capacidade dos AGLs em ativar o TLR-4 de uma maneira semelhante aos 
lipopolissacarídeos (LPS), endotoxinas presentes na membrana externa de bactérias gram-negativas, que são os ligantes clássicos desta via (CARICILLI et al., 2011).

A porção da endotoxina que se liga ao TLR-4 é chamada de lipídio A, e apresenta ácidos graxos saturados em sua composição (LEE et al., 2003). A retirada destes ácidos graxos livres do lipídio $A$ acarreta não só na completa perda da atividade da endotoxina, mas também em um comportamento antagonista do lipídio $A$ em relação às endotoxinas que contêm os AGLs saturados (KITCHENS; ULEVITCH; MUNFORD, 1992; MUNFORD; HALL, 1986). Além disso, lipídios A contendo AGLs insaturados são considerados não tóxicos (KRAUSS et al., 1989). Esta situação também ocorre quando AGLs são liberados a partir da lipólise. Lee et al. (2003) confirmaram um aumento da expressão de ciclo-oxigenase-2 (COX-2), uma enzima relacionada aos eventos da resposta inflamatória, a partir da estimulação da via do TLR-4 quando esta era ativada por ácido láurico, um ácido graxo saturado. Em contrapartida, houve inibição da COX-2 a partir da inibição da via do TLR-4 por ácidos graxos poliinsaturados, o que nos faz especular os AGLs saturados como responsáveis pela ativação deste receptor. Partindo desta premissa, foram realizados, também no soro, ensaios objetivando a verificação das quantidades destes dois ligantes. Os resultados obtidos não apontaram diferença no conteúdo de LPS entre os três grupos, ao contrário do conteúdo de AGL, aumentado significativamente no grupo TcC (tabela 4). Este fato sugere que os principais ligantes para ativação do TLR-4 na caquexia são os AGLs, em particular os saturados. Entretanto, não realizamos a determinação do tipo de $A G L$, quer no interstício, quer na circulação. O conteúdo aumentado de AGLs no soro nos fez cogitar a hipótese de que estes, no próprio tecido adiposo, poderiam estar atuando de maneira até mais preponderante do que os AGLs do soro, pela ativação aumentada das enzimas LHS e ATGL (SILVÉRIO, 2011).

A via do TLR-4 dependente do MyD88 está incrementada em outras situações em que há presença de inflamação (JUNG et al., 2012; ROSA NETO et al., 2010; SHI et al., 2006; VITSEVA et al., 2008), e como consequência, ativa a via do NFKB (COVERT et al., 2005). A subunidade p65, quando presente nos heterodímeros que migram ao núcleo (LAURENCIKIENE et al., 2001) é responsável pelo aumento da expressão gênica das citocinas relacionadas ao aumento de inflamação (SCHWARTZ; HERNANDEZ; MARK EVERS, 1999). 
A expressão gênica das proteínas TLR-4, MyD88 e TRAF-6 (todas da via do TLR-4), e da subunidade p65 do NFKB foi examinada, objetivando aferir um possível papel desta via na inflamação. Os resultados obtidos pelo grupo no presente estudo apontam que a expressão gênica das proteínas TLR-4, TRAF-6 e p65 encontrou-se aumentada no grupo $\mathrm{TcC}$ em relação ao grupo controle. Já a expressão gênica da proteína MyD88 apresentou-se aumentada no mesmo grupo, não só em relação ao grupo controle, mas também ao $\mathrm{TsC}$, sugerindo uma contribuição desta via na inflamação de pacientes caquéticos (figura 4). Estes dados oferecem uma perspectiva clara de que esta via está modulada na caquexia, contribuindo para a inflamação local do tecido adiposo e possivelmente, para a inflamação sistêmica. É importante ressaltarmos que, apesar do aparente papel das vias do TLR-4 e do $\mathrm{NFKB}$, outras vias podem também apresentar uma importante contribuição para a inflamação. A estimulação do TLR-4 leva também à ativação da família das MAPKs, incluindo JNK e p38, que ativam o ativador protéico-1 (AP-1), um fator de transcrição importante para as respostas inflamatórias (PULVERER et al., 1991).

Davis et al. (2008) demonstraram uma correlação positiva entre TLR-4, infiltração de macrófagos, proteína quimiotática de monócitos 1 (MCP-1) e o conteúdo nuclear de NFkB, tendo Kopp et al. (2009) relatado o importante papel da via do TLR-4 dependente do MyD88 na regulação de secreção de MCP-1 pelo tecido adiposo e ativação do NFkB. Baseado nestes dados e também em dados prévios (SHI et al., 2006), é possível sugerir que a geração de fatores inflamatórios neste tecido seja proveniente não só dos adipócitos, mas também de células do sistema imune recrutadas, como apresentado por Machado, Costa Rosa e Seelaender (2004), previamente.

O aumento da liberação de AGLs devido a um aumento na lipólise (induzida por citocinas pró-inflamatórias, que poderiam ser provenientes tanto do sangue quanto do próprio tecido), fornece ligantes para o TLR-4, que por sua vez induz a ativação da via do NFkB nos adipócitos e na fração celular vascular estromal, sendo esta fração a principal fonte de moléculas inflamatórias (CATALÁN et al., 2012), que podem atuar localmente, em adipócitos próximos ou tornar-se perceptíveis na corrente sanguinea (MOHAMED-ALI; PINKNEY; COPPACK, 1998). A figura 5 ilustra com a hipótese formulada. 
Figura 5 - llustração da hipótese formulada

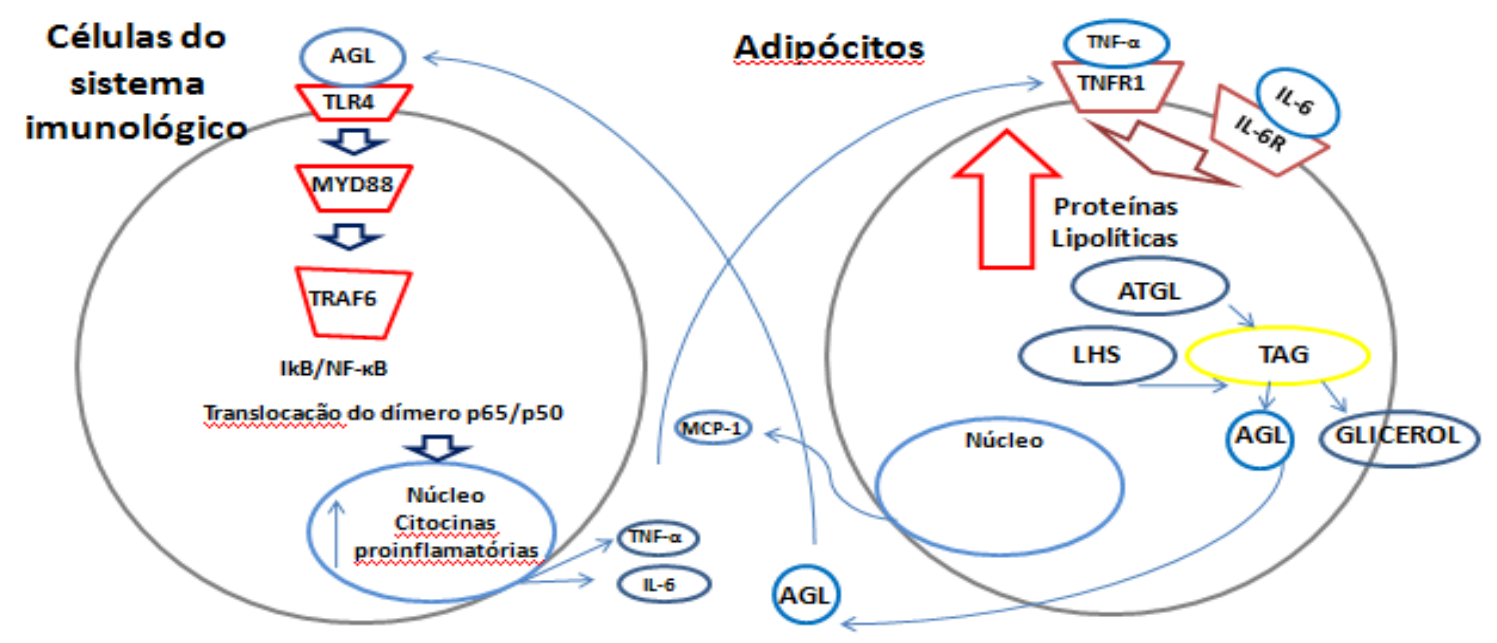

Fonte: Rosa Neto (não publicado)

Pode-se então sugerir, a partir destes dados, que os fatores inflamatórios podem contribuir tanto para a inflamação local (conferindo ao tecido adiposo papéis autócrinos e parácrinos) quanto sistêmicos (papel endócrino).

Esta cascata de eventos, ao menos na obesidade, acelera a alteração inflamatória no tecido adiposo (DE HEREDIA; GÓMEZ-MARTÍNEZ; MARCOS, 2012). É provável que os macrófagos $M 1$, que são células pró-inflamatórias, sejam um importante componente do tecido adiposo na caquexia, assim como na obesidade (MORRIS; SINGER; LUMENG, 2011), em que os macrófagos recrutados ao tecido adiposo exibiam predominantemente um fenótipo M1. Além disso, Orr et al. (2012) verificaram no tecido adiposo, um aumento da mudança do fenótipo de macrófagos M2 (não-inflamatórios) para M1, promovendo um estado inflamatório.

Em um quadro de insuficiência cardíaca crônica, uma inflamação sistêmica é associada à liberação de diversas citocinas inflamatórias, provenientes de diversos tecidos e células, incluindo macrófagos e células endoteliais (YNDESTAD et al., 2006), e os níveis elevados da expressão de TLR-4 nestas células sugerem uma possível contribuição do receptor na doença (DUNZENDORFER et al., 2004). Uma produção aumentada de citocinas pró-inflamatórias por sua vez aumentaria a lipólise (RYDEN et al., 2004), e é sabido, como mencionado, que AGLs aumentados ativam a via. 
Alguns autores apontam a influência do TLR-4 no desenvolvimento de algumas características na caquexia. Cannon et al. (2007) demonstraram que mesmo tendo ingerido mais ração e tendo tumores subcutâneos inferiores em tamanho em relação à camundongos nocaute para TLR-4, os camundongos wildtype desenvolveram maior caquexia; fato também observado por Vahle et al. (2012). Cannon et al. (2007) sugerem que a ausência de ativação do TLR-4 possa ser uma proteção contra um estado mais severo de caquexia, pelo fato de os camundongos nocaute para TLR-4 apresentarem uma habilidade reduzida em secretar citocinas pró-inflamatórias.

Esta idéia está em concordância com a reportada por Mantovani et al. (2008), que mostraram que a ativação da via do TLR-4 dependente do MyD88 acarretava em inflamação crônica, que é o principal fator no desenvolvimento da caquexia. Ruud et al. (2010) observaram que camundongos com deficiência na proteína MyD88 não desenvolveram anorexia relacionada à caquexia, enquanto que os camundongos wild-type sim. Huang et al. (2005) mostraram que a sinalização do TLR-4 induzida por LPS promoveu proliferação e invasão de células tumorais, resistência à apoptose e metástase. 


\section{CONCLUSÃO}

A partir dos critérios de classificação da caquexia utilizados neste estudo, os grupos foram selecionados de maneira adequada, condizente com as características descritas pela literatura. Os conteúdos aumentados de TNF- $\alpha$ e IL-6 no soro dos pacientes do grupo TcC, além de demonstrarem a existência de inflamação sistêmica, sugerem a contribuição desta citocinas no aumento da lipólise, verificada indiretamente a partir do conteúdo de AGLs e glicerol no soro destes pacientes. Os conteúdos elevados das mesmas citocinas no TAB subcutâneo dos pacientes do mesmo grupo indicam inflamação local deste tecido. Na inflamação associada à caquexia, aparentemente os AGLs, independentemente de serem provenientes do soro ou do próprio tecido, são os principais ativadores da via do TLR-4. Esta via, assim como a do NFKB, apresenta-se modulada na caquexia humana, sugerindo inflamação nos pacientes. Tomados em conjunto, os resultados demonstram que há alteração na via do TLR-4 na caquexia humana, apresentando a regulação terapêutica dessa via como alternativa de tratamento. 


\section{REFERÊNCIAS*}

ABREU, M. T.; ARDITI, M. Innate immunity and toll-like receptors: clinical implications of basic science research. J. Pediatr., v. 144, n. 4, p. 421-429, 2004.

AGUSTSSON, T.; RYDÉN, M.; HOFFSTED, T. J.; VAN HARMELEN, V.; DICKER, A.; LAURENCIKIENE, J.; ISAKSSON, B.; PERMERT, J.; ARNER, P. Mechanism of increased lipolysis in cancer cachexia. Cancer Res., v. 67, n. 11, p. 5531-5537, 2007.

AHIMA, R. S. Adipose tissue as na edocrine organ. Obesity, v. 14, n. 5, p. 242S249S, 2006.

ALEXOPOULOS, L.; THOMAS, V.; SCHNARE, M.; LOBET, Y.; ANQUITA, J.; SCHOEN, R. T.; MEDZHITOY, R.; FIKRIG,E.; FLAVELL, R. A. Hyporesponsiveness to vaccination with borrelia burgdorferi OspA in humans and in TLR1- and TLR2deficient mice. Nat. Med., v. 8, p. 878-884, 2002.

AMERICAN DIABETES ASSOCIATION. Standards of medical care in diabetes-2012. Diabetes Care, v. 35, p. 11-63, 2012.

ARGILÉS, J. M.; ALVAREZ, B.; LÓPEZ-SORIANO, F. J. The metabolic basis of cancer cachexia. Med. Res. Rev., v. 17, n. 5, p.477-498, 1997.

ARGILÉS, J. M.; BUSQUETS, S.; LÓPEZ-SORIANO, F. J. Cytokines in the pathogenesis of cancer cachexia. Curr. Opin. Clin. Nutr. Metab. Care, v. 6, p. 401406, 2003.

ARGILÉS, J. M.; MOORE-CARRASCO, R.; BUSQUETS, S.; LOPEZ-SORIANO, F. J. Catabolic mediators as targets for cancer cachexia. Drug Discov. Today, v. 8, n. 18, p. 838-844, 2003.

ARGILÉS, J. M.; LÓPEZ-SORIANO, F. J.; BUSQUETS, S. Novel approaches to the treatment of cachexia. Drug Discovery Today, v. 13, p. 73-78, 2008.

ARNER, P. The adipocyte in insulin resistance: key molecules and the impact of the thiazolidinediones. Trends Endocrinol. Metab., v. 14, p. 137-45, 2003.

BAKER, R. G.; HAYDEN, M. S.; GHOSH, S. NF-KB, inflammation, and metabolic disease. Cell Metab., v. 13, p. 11-22, 2011.

BARNES, P. J.; KARIN, M. Nuclear factor-kappaB: a pivotal transcription factor in chronic inflammatory diseases. N. Engl. J. Med., v. 336, n. 15, p. 1066-1071, 1997.

\footnotetext{
* De acordo com:

ASSOCIAÇÃO BRASILEIRA DE NORMAS TÉCNICAS. NBR 6023: informação e documentação: referências: elaboração. Rio de Janeiro, 2002.
} 
BASIC LOCAL ALIGNMENT SEARCH. BLAST. Disponível em: <http://blast.ncbi.nlm.nih.gov/Blast.cgi/>. Acesso em: 10 fev. 2012.

BATRA, A.; PIETSCH, J.; FEDKE I.; GLAUBEN, R.; OKUR, B.; ZEITZ, M.; IEGMUND, B. Leptin-dependent toll-like receptor expression and responsiveness in preadipocytes and adipocytes. Am. J. Pathol., v. 170, p. 1931-1941, 2007.

BATISTA JUNIOR, M. L.; PERES, S. B.; MCDONALD, M. E.; ALCANTARA, P. S.; OLIVAN, M.; OTOCH, J. P.; FARMER, S. R.; SEELAENDER, M. Adipose tissue inflammation and cancer cachexia: possible role of nuclear transcription factors. Cytokine, v. 57, p. 9-16, 2012.

BATISTA JUNIOR, M. L.; OLIVAN, M.; ALCANTARA, P. S. M.; SANDOVAL, R.; PERES, S. B.; NEVES, R. X.; SILVERIO, R.; MAXIMIANO, L. F.; OTOCH, J. P.; SEELAENDER, M. Adipose tissue-derived factors as potential biomarkers in cachectic cancer patients. Cytokine, v. 61, p. 532-539, 2013.

BAUMANN, H.; GAULDIE, J. The acute phase response. Immunol. Today, v. 15, n. 2, p. 74-80, 1994.

BENNANI-BAITI, N.; DAVIS, M. P. Cytokines and cancer anorecia cachexia syndrome. Am. J. Hosp. Palliat. Care, v. 25, p. 407-411, 2008.

BERTEVELLO, P. S. E.; SEELAENDER, M. C. L. Heterogeneous response of adipose tissue to cancer cachexia. Brazilian Journal of Medical and Biological Research, v. 34, p. 1161-1167, 2001.

BING, C. Lipid mobilization in cachexia: mechanisms and mediators. Current Opinion in Supportive and Palliative Care, v. 5, p. 356-360, 2011.

BING, C.; TRAYHURN, P. Regulation of adipose tissue metabolism in cancer cachexia. Curr. Opin. Clin. Nutr. Metab. Care, v. 11, n. 3, p. 201-207, 2008.

BOTION, L. M.; BRASIER, A. R.; TIAN, B.; UDUPI, V.; GREEN, A. Inhibition of proteasome activity blocks the ability of TNFa to down-regulate Gi proteins and stimulate lypolisis. Endocrinology, v. 142, p. 5069-5075, 2001.

BRADFORD, M. M. A rapid and sensitive method for the quantitation of microgram quantities of protein utilizing the principle of protein-dye binding. Anal. Biochem., v. 72, p. 248-254, 1976.

BRUERA, E.; SELMSER, P.; PEREIRA, J.; BRENNEIS, C. Bus rounds for palliative care education in the community. CMAJN, v. 15, n. 6, p. 701-702, 1997.

BYERLEY, L. O.; LEE, S. H.; REDMANN, S.; CULBERSON, C.; CLEMENS, M.; LIVELY, M. O. Evidence for a novel serum factor distinct from zinc alpha-2 glycoprotein that promotes body fat loss early in the development of cachexia. Nutr. Cancer, v. 62, n. 4, p. 484-494, 2010.

CANNON, T. Y.; GUTTRIDGE, D.; DAHLMAN, J.; GEORGE, J. R.; LAI, V.; SHORES, C.; BUZKOVÁ, P.; COUCH, M. E.The effect of altered toll-like receptor 4 
signaling on cancer cachexia. Arch. Otolaryngol. Head Neck Surg., v. 133, n. 12, p. 1263-1269, 2007.

CARICILLI, A. M.; PICARDI, P. K.; DE ABREU, L. L.; UENO, M.; PRADA, P. O.; ROPELLE, E. R.; HIRABARA, S. M.; CASTOLDI, Â.; VIEIRA, P.; CAMARA, N. O.; CURI, R. L.; CARVALHEIRA, J. B.; SAAD, M. J. Gut microbiota is a key modulator of insulin resistance in TLR 2 knockout mice. PLoS. Biol., v. 9, n. 12, p. 1-12, 2011.

CATALÁN, V.; GÓMEZ-AMBROSI, J.; RODRÍGUEZ, A.; RAMÍREZ, B.; ROTELLAR, F.; VALENTÍ, V.; SILVA, C.; GIL, M. J.; SALVADOR, J.; FRÜHBECK, G. Increased tenascin $\mathrm{C}$ and toll-like receptor 4 levels in visceral adipose tissue as a link between inflammation and extracellular matrix remodeling in obesity. J. Clin. Endocrinol. Metab., v. 97, n. 10, p. E1880-1889, 2012.

COPPACK, S. W. Pro-inflammatory cytokines and adipose tissue. Proc. Nutr. Soc., v. 60 , n. 6 , p. 349-356, 2001.

COVERT, M. W.; LEUNG, T. H.; GASTON, J. E.; BALTIMORE, D. Achieving stability of lipopolysaccharide-induced NF-kappaB activation. Science, v., 309, n. 5742, p. 1854-1857, 2005.

CREELY, S. J.; MCTERNAN, P. G.; KUSMINSKI, C. M.; FISHER, F. M. , DA SILVA, N. F.; KHANOLKAR, M.; EVANS, M.; HARTE, A. L.; KUMAR, S. Lipopolysaccharideactivates an innate immune system response inhuman adipose tissue in obesity and type 2 diabetes. Am. J. Physiol. Endocrinol. Metab., v. 292, n. 3, p. E740-747, 2007.

DAVIS, J. E.; GABLER, N. K.; WALKER-DANIELS, J.; SPURLOCK, M. E. TIr-4 deficiency selectively protects against obesity induced by diets high in saturated fat. Obesity, v. 16, n. 6, p. 1248-1255, 2008.

DE HEREDIA, F. P.; GÓMEZ-MARTÍNEZ, S.; MARCOS, A. Obesity, inflammation and the immune system. Proc. Nutr. Soc., v. 71, n. 2, p. 332-338, 2012.

DEIULIIS, J.; SHAH, Z.; SHAH, N.; NEEDLEMAN, B.; MIKAMI, D.; NARULA, V.; PERRY, K.; HAZEY, J.; KAMPFRATH, T.; KOLLENGODE, M.; SUN, Q.; SATOSKAR, A. R.; LUMENG, C.; MOFFATT-BRUCE, S.; RAJAGOPALAN, S. Visceral adipose inflammation in obesity is associated with critical alterations in tregulatory cell numbers. PLoS. One, v. 6, p. e16376, 2011.

DELANO, M. J.; MOLDAWER, L. L. The origins of cachexia in acute and chronic inflammatory diseases. Nutr. Clin. Pract., v. 21, p. 68-81, 2006.

DEWYS, W. D. Weight loss and nutritional abnormalities in cancer patients: incidence, severity and significance. Clinics in Oncology, v. 5, n. 2, p. 251-261, 1986.

DODSON, S.; BARACOS, V. E.; JATOI, A.; EVANS, W. J.; CELLA, D.; DALTON, J. T.; STEINER, M. S. Muscle wasting in cancer cachexia: clinical implications, 
diagnosis, and emerging treatment strategies. Annu. Rev. Med., v. 62, p. 265-279, 2011.

DUNZENDORFER, S.; LEE, H. K.; SOLDAU, K.; TOBIAS, P. S. Toll-like receptor 4 functions intracellularly in human coronary artery endothelial cells: roles of LBP and sCD14 in mediating LPS responses. Faseb. J., v. 18, n. 10, p. 1117-1119, 2004.

ESPOSITO, K.; PONTILLO, A.; GIUGLIANO F.; GIUGLIANO, G.; MARFELLA, R.; NICOLETTI, G.; GIUGLIANO, D. Association of low interleukin-10 levels with the metabolic syndrome in obese women. J. Clin. Endocrinol. Metab., v. 88, n. 3, p. 1055-1058, 2003.

EVANS, R. D.; WILLIAMSON, D. H. Tissue-specific effects of rapid tumour growth on lipid metabolism in the rat during lactation and on litter removal. Biochem. J., v. 252, p. 65-72, 1988.

FANTUZZI, G. Adipose tissue, adipokines, and inflammation. J. Allergy Clin. Immunol., v. 115, n. 5, p. 911-919, 2005.

FEARON, K. C. H.; MOSES, A. G. W. Cancer cachexia. Int. J. Cardiol., v. 85, p.7381, 2002.

FEARON, K. C.; HANSELL, D. T.; PRESTON, T.; PLUMB, J. A.; DAVIES, J.; SHAPIRO, D.; SHENKIN, A.; CALMAN, K. C.; BURNS, H. J. Influence of whole body protein turnover rate on resting energy expenditure in patients with cancer. Cancer res., v. 48, n. 9, p. 2590-2595, 1988.

FEARON, K.; STRASSER, F.; ANKER, S. D.; BOSAEUS, I.; BRUERA, E.; FAINSINGER, R. L.; JATOI, A.; LOPRINZI, C.; MACDONALD, N.; MANTOVANI, G.; DAVIS, M.; MUSCARITOLI, M.; OTTERY, F.; RADBRUCH, L.; RAVASCO, P.; WALSH, D.; WILCOCK, A.; KAASA, S.; BARACOS, V. E. Definition and classification of cancer cachexia: an international consensus. Lancet. Oncol., v. 12, n. 5, p. 489495, 2011.

FOGELSTRAND, L.; HULTHE, J.; HULTEN, L. M.; WIKLUND, O.; FAGERBERG, B. Monocytic expression of CD14 and CD18, circulating adhesion molecules and inflammatory markers in women with diabetes mellitus and impaired glucose tolerance. Diabetologia, v. 47, n. 11, p. 1948-1952, 2004.

FONG, Y. C.; MAA, M. C.; TSAI, F. J.; CHEN, W. C.; LIN, J. G.; JENG, L. B.; YANG, R. S.; FU, W. M.; TANG, C. H. Osteoblast-derived TGF-beta1 stimulates IL-8 release through AP-1 and NF-kappaB in human cancer cells. J. Bone Miner. Res., v. 23, n. 6, p. 961-970, 2008.

FOULADIUN, M.; KÖRNER, U.; BOSAEUS, I.; DANERYD, P.; HYLTANDER, A.; LUNDHOLM, K. G. Body composition and time course changes in regional distribution of fat and lean tissuein unselected cancer patients on palliative care correlations with food intake, metabolism, exercise capacity, and hormones. Cancer, v. 103 , n. 10, p. 2189-2198, 2005. 
FRASER, C. C. Exploring the positive and negative consequences of nf-kb inhibition for the treatment of human disease. Cell Cycle, v. 5, n. 11, p. 1160-1163, 2006.

GAO, Z.; ZHANG, X.; ZUBERI, A.; HWANG, D.; QUON, M. J.; LEFEVRE, M.; YE, J. Inhibition of insulin sensitivity by free fatty acids requires activation of multiple serine kinases in 3T3-L1 adipocytes. Mol. Endocrinol., v. 18, n. 8, p. 2024-2034, 2004.

GARG, A.; AGGARWAL, B. B. transcription factor-kappaB as a target for cancer drug development. Leukemia, v. 16, n. 6, p. 1053-1068, 2002.

HUANG, B.; ZHAO, J.; LI, H.; HE, K. L.; CHEN, Y.; CHEN, S. H.; MAYER, L.; UNKELESS, J. C.; XIONG, H. Toll-Like receptors on tumor cell facilitate evasion of immune surveillance. Cancer Res., v. 65, n. 12, p. 5009-5014, 2005.

HUSSEY, S. E.; LIANG, H.; COSTFORD, S. R.; KLIP, A.; DEFRONZO, R. A.; SANCHEZ-AVILA, A.; ELY, B.; MUSI, N. TAK-242, a small-molecule inhibitor of tolllike receptor 4 signalling, unveils similarities and differences in lipopolysaccharideand lipid-induced inflammation and insulin resistance in muscle cells. Biosci. Rep., v. 33, p. 37-47, 2012.

INSTITUTO NACIONAL DO CÂNCER. TNM: classificação de tumores malignos. INCA; 2004. 254 p. Traduzido por Ana Lúcia Amaral Eisenberg.

JUNG, S.; PARK, H.; KIM, K.;CHOJ, W. H.; AHN, C. W.; KIM, B. T.; KIM, S. M.; LEE, S. Y.; AHN, S. M.; KIM, Y. K.; KIM, H. J.; KIM, D. J.; LEE, K. W. Effect of weight loss on some serum cytokines in human obesity: increase in IL-10 after weight loss. $\mathbf{J}$. Nutri. Biochem., v. 19, n. 6, p. 371-375, 2008.

JUNG, S. A.; CHOI, M.; KIM, S.; YU, R.; PARK, T. Cinchonine prevents high-fat-dietinduced obesity through downregulation of adipogenesis and adipose inflammation. PPAR. Res., 541204, 2012.

KANAYAMA, A.; SETH, R. B.; SUN, L.; EA, C. K.; HONG, M.; SHAITO, A.; CHIU, Y. H.; DENG, L.; CHEN, Z. J. TAB2 and TAB3 activate the NF-kappaB pathway through binding to polyubiquitin chains. Moll. Cell, v. 15, n. 4, p. 535-548, 2004.

KAWAI, T.; AKIRA, S. Signaling to NF-kappaB by toll-like receptors. Trends Mol. Med., v. 13, n. 11, p. 460-469, 2007.

KEREM, M.; FERAHKOSE, Z.; YILMAZ, U. T.; PASAOGLU, H.; OFLUOGLU, E.; BEDIRLI, A.; SALMAN, B.; SAHIN, T. T.; AKIN, M. Adipokines and ghrelin in gastric cancer cachexia. World J. Gastroenterol., v. 14, n. 23, p. 3633-3641, 2008.

KITCHENS, R. L.; ULEVITCH, R. J.; MUNFORD, R. S. Lipopolysaccharide (LPS) partial structures inhibit responses to LPS in a human macrophage cell line without inhibiting LPS uptake by a CD14- mediated pathway. J. Exp. Med., v. 176, n. 2, p. 485-494, 1992.

KOPP, E. B.; MEDZHITOV, R. The toll-receptor family and control of innate immunity. Curr. Opin. Immunol., v. 11, p. 13-18, 1999. 
KOPP, A.; BUECHLER, C.; NEUMEIER, M.; WEIGERT, J.; ASLANIDIS, C.; SCHÖLMERICH, J.; SCHÄFFLE, A. Innate immunity and adipocyte function: ligandspecific activation of multiple toll-like receptors modulates cytokine, adipokine, and chemokine secretion in adipocytes. Obesity, v. 17, n. 4, p. 648-656, 2009.

KOPP, A.; BUECHLER, C.; BALA, M.; NEUMEIER, M.; LMERICH, J. S.; SCHAEFFLER, A. Toll-like receptor ligands cause proinflammatory and prodiabetic activation of adipocytes via phosphorylation of extracellular signal-regulated kinase and $\mathrm{c}$-jun $\mathrm{n}$-terminal kinase but not interferon regulatory factor-3. Endocrinology, v. 151, n. 3, p. 1097-1108, 2010.

KRAUSS, J. H.; SEYDEL, U.; WECKESSER, J.; MAYER, H. Structural analysis of the nontoxic lipid $A$ of rhodobacter capsulatus 37b4. Eur. J. Biochem., v. 180, n. 3, p. 519-526, 1989.

KRUTZIK, S. R.; OCHOA, M. T.; SIELING, P. A.; UEMATSU, S.; NG, Y. W.; LEGASPI, A.; LIU, P. T.; COLE, S. T.; GODOWSKI, P. J.; MAEDA, Y.; SARNO, E. N.; NORGARD, M. V.; BRENNAN, P. J.; AKIRA, S.; REA, T. H.; MODLIN, R. L.; Activation and regulation of toll-like receptors 2 and 1 in human leprosy. Nat. Med., v. 9, n. 5 , p. 525-532, 2003.

KÜPER, C.; BECK, F. X.; NEUHOFER, W. Toll-like receptor 4 activates NF-KB and MAP kinase pathways to regulate expression of proinflammatory COX-2 in renal medullary collecting duct cells. Am. J. Physiol. Renal Physiol., v. 302, p. 38-56, 2011.

LAIRD, B. J.; SCOTT, A. C.; COLVIN, L. A.; MCKEON, A. L.; MURRAY, G. D.; FEARON, K. C.; FALLON, M. T. Pain, depression, and fatigue as a symptom cluster in advanced cancer. J. Pain Symptom Manage, v. 42, p. 1-11, 2011.

LANG, C. H.; SILVIS, C.; DESHPANDE, N.; NYSTROM, G.; FROST, R. A. Endotoxin stimulates in vivo expression of inflammatory cytokines tumor necrosis factor alpha, interleukin-1beta, -6, and high-mobility-group protein-1 in skeletal muscle. Shock, v. 19 , p. 538-546, 2003.

LAURENCIKIENE, J.; VAN HARMELEN, V.; ARVIDSSON NORDSTROM, E.; DICKER, A.; BLOMQVIST, L.; NASLUND, E.; LAWRENCE, T.; GILROY, D. W.; COLVILLE-NASH, P. R.; WILLOUGHBY, D. A. Possible new role for NF-kappaB in the resolution if inflammation. Nat. Med., v. 7, n. 12, p. 1291-1297, 2001.

LEE, J. Y.; PLAKIDAS, A.; LEE, W. H.; HEIKKINEN, A.; CHANMUGAM, P.; BRAY, G.; HWANG, D. H. Differential modulation of toll-like receptors by fatty acids: preferential inhibition by $\mathrm{n}-3$ polyunsaturated fatty acids. Journal of Lipid Research, v. 44, n. 3, p. 479-486, 2003.

LIRA, F. S.; ROSA NETO, J. C.; ZANCHI, N. E.; YAMASHITA, A. S.; LOPES, R. D.; LOPES, A. C.; BATISTA JUNIOR, M. L.; SEELAENDER, M. Regulation of 
inflammation in the adipose tissue in cancer cachexia: effect of exercise. Cell Biochem. Funct., v. 27, n. 2, p. 71-75, 2009.

LIVAK, K. J.; SCHMITTGEN, T. D. Analysis of relative gene expression data using real-time quantitative PCR and the 2(- Delta Delta C(T)) Method. Methods, v. 25, n. 4, p. 402-408, 2001.

LUMENG, C. N.; DEYOUNG, S. M.; SALTIEL, A. R. Macrophages block insulin action in adipocytes by altering expression of signaling and glucose transport proteins. Am. J. Physiol. Endocrinol. Metab., v. 292, p. E166-174, 2007.

LUNDHOLM, K.; DANERYD, P.; KORNER, U.; HYLTANDER, A.; BOSAEUS, I. Evidence that long-term COX-treatment improves energy homeostasis and body composition in cancer patients with progressive cachexia. Int. J. Oncol., v. 24, n. 3, p. 505-512, 2004.

MACHADO, A. P.; COSTA ROSA, L. F.; SEELAENDER, M. C. Adipose tissue in walker 256 tumour-induced cachexia: possible association between decreased leptin concentration and mononuclear cell infiltration. Cell Tissue Res., v. 318, p. 503-514, 2004.

MALLARD, C. Innate immune regulation by toll-like receptors in the brain. ISRN. Neurol., p. 701950, 2012.

MANTOVANI, A.; ROMERO, P.; PALUCKA, A. K.; MARINCOLA, F. M. Tumour immunity: effector response to tumour and role of the microenvironment. Lancet, $v$. 371, p. 771-783, 2008.

MCMILLAN, D. C. An inflammation-based prognostic score and its role in the nutrition-based management of patients with cancer. Proceedings of the Nutrition Society, v. 67, n. 3, p., 257-262, 2008.

MCMILLAN, D. C. Systemic inflammation, nutritional status and survival in patients with cancer. Curr. Opin. Clin. Nutr. Metab. Care, v. 12, p. 223-226, 2009.

MEDZHITOV, R.; JANEWAY, C. A. Jr. Innate immune recognition and control of adaptive immune responses. Semin. Immunol., v. 10, n. 5, p. 351-353, 1998.

MICHELSEN, K. S.; DOHERTY, T. M.; SHAH, P. K.; ARDITI, M. TLR signaling: an emerging bridge from innate immunity to atherogenesis. J. Immunol., v. 173, n. 10, p. 5901-5907, 2004.

MILLER, S. I.; ERNST, R. K.; BADER, M. W. LPS, TLR4 and infectious disease diversity. Nat. Rev. Microbiol., v. 3, p. 36-46, 2005.

MOHAMED-ALI, V.; PINKNEY, J. H.; COPPACK, S. W. Adipose tissue as an endocrine and paracrine organ. Int. J. Obes. Relat. Metab. Disord., v. 22, n. 12, p. 1145-1158, 1998. 
MONTAGUE, C. T. Adipose depot-specific effects of PPAR- $\gamma$ agonists: a consequence of differential expression of PPAR- $\gamma$ in adipose tissue depots? Diabetes Obes. Metab., v. 4, n. 6, p. 356-361, 2002.

MORRIS, D. L.; SINGER, K.; LUMENG, C. N. Adipose tissue macrophages: phenotypic plasticity and diversity in lean and obese states. Curr. Opin. Clin. Nutr. Metab. Care, v. 14, n. 4, p. 341-346, 2011.

MULLIGAN, H. D.; TISDALE, M. J. Metabolic substrate utilization by tumour and host tissues in cancer cachexia. Biochem. J., v. 277, pt. 2, p. 321-326, 1991.

MUNFORD, R. S.; HALL, C. L. Detoxification of bacterial lipopolysaccharides (endotoxins) by a human neutrophil enzyme. Science, v. 234, n. 4773, p. 203-205, 1986.

MURPHY, R. A.; WIKE, M. S.; PERRINE, M.; PAWLOWICZ, M.; MOURTZAKIS, M.; LIEFFERS, J. R.; MANESHGAR, M.; BRUERA, E.; CLANDININ, M. T.; BARRACOS, V. E.; MAZURAK, V. C. Loss of adipose tissue and plasma phospholipids: relationship to survival in advanced cancer patients. Clin. Nutr., v. 29, n. 4, p. 482487, 2010.

NACIONAL CENTER FOR BIOTECHNOLOGY INFORMATION. GenBank. Disponível em: <http://www.ncbi.nlm.nih.gov/genbank/>. Acesso em: 6 fev. 2012.

NACIONAL CENTER FOR BIOTECHNOLOGY INFORMATION. Spidey. Disponível em: <http://www.ncbi.nlm.nih.gov/spidey/spideyweb.cgi/>. Acesso em: 7 fev. 2012.

OGAWA, H.; NIELSEN, S.; KAWAKAMI, M. Cachectin/tumor necrosis factor and interleukin-1 show different modes of combined effect on lipoprotein lipase activity and intracellular lipolysis in 3T3-L1 cells. Biochim. Biophys Acta, v. 1003, n. 2, p. 131-135, 1989.

O'NEILL, L.A.; GREENE, C. Signal transduction pathways activated by the IL-1 receptor family: ancient signaling machinery in mammals, insects, and plants. J. Leukoc. Biol., v. 63, p. 6, p. 650-657, 1998

O'RIORDAIN, M. G.; FALCONER, J. S.; MAINGAY, J.; FEARON, K.C.; ROSS, J. A. Peripheral blood cells from weight-losing cancer patients control the hepatic acute phase response by a primarily interleukin- 6 dependent mechanism. Int. J. Oncol., v. 15, n. 4, p. 823-827, 1999.

ORR, J. S.; PUGLISI, M. J.; ELLACOTT, K. L.; LUMENG, C. N.; WASSERMAN, D. H.; HASTY, A H. Toll-like receptor 4 deficiency promotes the alternative activation of adipose tissue macrophages. Diabetes, v. 61, n. 11, p. 2718-2727, 2012.

OSHIMA, H.; OSHIMA, M. The inflammatory network in the gastrointestinal tumor microenvironment: lessons from mouse models. J. Gastroenterol., v. 47, n. 2, p. 97106, 2012. 
POND, C. M. Physiological specialisation of adipose tissue. Prog. Lipid. Res., v. 38, n. 3, p. 225-248, 1999.

PULVERER, B. J.; KYRIAKIS, J. M.; AVRUCH, J.; NIKOLAKAKI, E.; WOODGETT, J. R. Phosphorylation of c-Jun mediated by MAP kinases. Nature, v. 353, n. 6345, p. 670-674, 1991.

RIDKER, P. M.; HENNEKENS, C. H.; BURING, J. E.; RIFAI, N. C-Reactive protein and other markers of inflammation in the prediction of cardiovascular disease in women. N. Engl. J. Med., v. 342, n. 12, p. 836-843, 2000.

ROSA NETO, J. C.; LIRA, F. S.; EGUCHI, R.; PIMENTEL, G. D.; VENÂNCIO, D. P.; CUNHA, C. A.; OYAMA, L. M.; SEELAENDER, M.; NASCIMENTO, C. M. O. Exhaustive exercise increased inflammatory response via toll-like receptor 4 and NFkBp65 pathway in adipose tissue in rats. J. Cell Physiol., v. 226, n. 6, p. 1604-1607, 2010.

ROSS, R. Atherosclerosis - an inflammatory disease. N. Engl. J. Med., v. 340, n. 2, p. 115-126, 1999.

RUUD, J.; BÄCKHED, F.; ENGBLOM, D.; BLOMQVIST, A. Deletion of the gene encoding MyD88 protects from anorexia in a mouse tumor model. Brain Behav. Immun., v. 24, n. 4, p. 554-557, 2010.

RYDEN, M.; DICKER, A.; VAN HARMELEN, V.; HAUNER, H.; BRUNNBERG, M.; PERBECK, L.; LONNQVIST, F.; ARNER, P. Mapping of early signaling events in tumor necrosis factor-alpha-mediated lypolisys in human fat cells. J. Biol. Chem., v. 277, n. 2, p. 1085-1091, 2002.

RYDEN, M.; ARVIDSSON, E.; BLOMQVIST, L.; PERBECK, L.; DICKER, A.; ARNER, $P$. Targets for TNFa-induced lipolysis in human adipocytes. Biochem. Biophys Res. Commun., v. 318, p. 168-175, 2004.

RYDEN, M.; AGUSTSSON, T.; LAURENCIKIENE, J.; BRITTON, T.; SJÖLIN, E.; ISAKSSON, B.; PERMERT, J.; ARNER, P. Lipolysis-not inflammation, cell death, or lipogenesis is involved in adipose tissue loss in cancer cachexia. Cancer, v. 113, n. 7, p. 1695-1704, 2008.

SCHNARE, M.; HOLT, A. C.; TAKEDA, K.; AKIRA, S.; MEDZHITOV, R. Recognition of CpG DNA is mediated by signaling pathways dependent on the adaptor protein MyD88. Curr. Biol., v. 10, n. 18, p. 1139-1142, 2000.

SCHWARTZ, S. A.; HERNANDEZ, A.; MARK EVERS, B. The role of NF-kappaB proteins in cancer: implications for novel treatment satrategies. Surg. Oncol., v. 8, n. 3, p. 143-53, 1999.

SEELAENDER, M.; BATISTA JUNIOR, M. Heterogeneous response of rat and human adipose tissue in cancer cachexia. J. Endocrinol., v. 1, p. 61-62, 2010 [5 ${ }^{\text {th }}$ Cachexia Conference; 2009; Barcelona]. 
SHI, H.; KOKOEVA, M. V.; INOUYE, K.; TZAMELI, I.; YIN, H.; FLIER, J. S. TLR4 links innate immunity and fatty acid-induced insulin resistance. The Journal of Clinical Investigation, v. 116, n. 11, p. 3015-3025, 2006.

SILVÉRIO, R. A modulação da lipase de triacilglicerol do adipócito (ATGL) e da perilipina 1 contribui para $o$ aumento da lipólise em pacientes caquéticos. 2011. 116 f. Tese (Doutorado em Biologia Celular e Tecidual) - Instituto de Ciências Biomédicas, Universidade de São Paulo, São Paulo, 2011.

SUGANAMI, T.; OGAWA, Y. Adipose tissue macrophages: their role in adipose tissue remodeling. J. Leukoc. Biol., v. 88, p. 33-39, 2010.

SUGANAMI, T.; TANIMOTO-KOYAMA, K.; NISHIDA, J.; ITOH, M.; YUAN, X.; MIZUARAU, S.; KOTANI, H.; YAMAOKA, S.; MIYAKE, K.; AOE, S.; KAMEI, Y.; OGAWA, Y. Role of the toll-like receptor $4 /$ NFKB pathway in saturated fatty acidinduced inflammatory changes in the interaction between adipocytes and macrophages. Arterioscler Thromb. Vasc. Biol., v. 27, p. 84-91, 2007.

TAKEDA, K.; AKIRA, S. Toll-like receptors in innate immunity. Int. Immunol., v. 17, p. 1-14, 2005.

TAN, B. H.; ROSS, J. A.; KAASA, S.; SKORPEN, P.; FEARON, K. C.; EUROPEAN PALLIATIVE CARE RESEARCH COLLABORATIVE. Identification of possible genetic polymorphisms involved in cancer cachexia: a systematic review. J. Genet., v. 90 , p. 165-177, 2011.

TAYEK, J. A. A review of cancer cachexia and abnormal glucose metabolism in humans with cancer. J. Am. Coll. Nutr., v. 11, n. 4, p. 445-456, 1992.

TISDALE, M. Wasting in cancer. J. Nutr., v. 129, p. 2438-2468, 1999.

TISDALE, M. J. Catabolism of skeletal muscle proteins and its reversal in cancer cachexia. Nestle Nutr. Workshop Ser. Clin. Perform. Programme, v. 4, p. 135143, 2000.

TISDALE, M. J. Tumor-host interactions. J. Cell Biochem., v. 93, n. 5, p. 871-877, 2004.

TISDALE, M. J. Mechanisms of cancer cachexia. Physiol. Rev., v. 89, n. 2, p. 381410, 2009.

TRAYHURN, P.; WOOD, I. S. Signalling role of adipose tissue: adipokines and inflammation in obesity. Biochem. Soc. Trans., v. 33, pt. 5, p. 1078-1081, 2005.

TRIANTAFILOU, M.; BRANDENBURG, K.; KUSUMOTO, S.; FUKASE, K.; MACKIE, A.; SEYDEL, U.; TRIANTAFILOU, K. Combinational clustering of receptors following stimulation by bacterial products determines lipopolysaccharide responses. Biochem. J., v. 381, pt. 2, p. 527-536, 2004.

TSUKUMO, D. M.; CARVALHO FILHO, M. A.; CARVALHEIRA, J. B.; PRADA, P. O.; HIRABARA, S. M.; SCHENKA, A. A.; ARAUJO, E. P.; VASSALLO, J.; CURI, R.; 
VELLOSO, L. A.; SAAD, M. J. Loss-of-function mutation in toll-like receptor 4 prevents diet-induced obesity and insulin resistance. Diabetes, v. 56, n. 8 , p. 19861998, 2007.

UNIVERSITY OF MASSACHUSETTS MEDICAL SCHOOL. Primer 3. Disponível em: <http://biotools.umassmed.edu/bioapps/primer3_www.cgi/>. Acesso em: 8 fev. 2012.

VAHLE, A. K.; KEREM, A.; OZTÜRK, E.; BANKFALVI, A.; LANG, S.; BRANDAU, S. Optimization of an orthotopic murine model of head and neck squamous cell carcinoma in fully immunocompetent mice - role of toll-like-receptor 4 expressed on host cells. Cancer Lett., v. 317, n. 2, p. 199-206, 2012.

VAN HAEHLING, S.; GENTH-ZOTZ, S.; ANKER, S. D.; VOLK, H. D. Cachexia a therapeutic approach beyond cytokine antagonism. Int. J. Cardiol., v. 85, p. 173183, 2002.

VITSEVA, O. I.; TANRIVERDI, K.; TCHKONIA, T. T.; KIRKLAND, J. L.; MCDONNELL, M. E.; APOVIAN, C. M.; FREEDMAN, J.; GOKCE, N. Inducible tolllike receptor and NF-kappaB regulatory pathway expression in human adipose tissue. Obesity, v. 16, n. 5, p. 932-937, 2008.

WU, D.; REN, Z.; PAE, M.; GUO, W.; CUI, X.; MERRILL, A. H.; MEYDANI, S. N. Aging up-regulates expression of inflammatory mediators in mouse adipose tissue. $\mathbf{J}$ Immunol., v. 179, n. 7, p. 4829-4839, 2007.

YANG, Y. S.; SONG, H. D.; SHI, W. J.; HU, R. M.; HAN, Z. G.; CHEN, J. L. Chromosome localization analysis of genes strongly expressed in human visceral adipose tissue. Endocrine, v. 18, p. 57-66, 2002.

YNDESTAD, A.; DAMÅS, J. K.; OIE, E.; UELAND, T.; GULLESTAD, L.; AUKRUST, $P$. Systemic inflammation in heart failure - the whys and wherefores. Heart Fail Rev., v. 11, p. 83-92, 2006.

ZHANG, Y.; PROENCA, R.; MAFFEI, M.; BARONE, M.; LEOPOLD, L.; FRIEDMAN, J. M. Positional cloning of the mouse obese gene and its human homologue. Nature, v. 372, n. 6505, p. 406-407, 1994.

ZHANG, G.; GHOSH, S. Toll-like receptor-mediated NF-KB activation: a phylogenetically conserved paradigm in innate immunity. The Journal of Clinical Investigation, v. 107, p. 13-19, 2001.

ZHU, J.; MOHAN, C. Toll-Like receptor signaling pathways-therapeutic opportunities. Mediators of Inflammation, v. 2010, p. 1-7, 2010. 


\section{ANEXO A \\ EORTC QLQ-C30 (version3)}

Gostaríamos de conhecer alguns pormenores sobre si e sua saúde. Responda você mesmo/a, por favor, a todas as perguntas fazendo um círculo à volta do número que melhor se aplica ao seu caso. Não há respostas certas ou erradas. A informação fornecida é estritamente confidencial.

Escreva as iniciais do seu nome:

A data de nascimento (dia/mês/ano):

A data de hoje (dia/mês/ano):

Não Um Bastante Muito pouco

1. Custa-Ihe fazer esforços mais violentos, por $11 \quad 2 \quad 4$ exemplo, carregar um saco de compras pesado ou uma mala?

2. Custa-lhe percorrer uma grande distância a pé?

3. Custa-lhe dar um pequeno passeio a pé, fora de casa?

4. Precisa de ficar na cama ou numa cadeira durante o dia?

5. Precisa que o ajudem a comer, a vestir-se, a lavar-se ou a ir à casa de banho?

Durante a última semana:

Não Um Bastante Muito pouco

6. Sentiu-se limitado/a no seu emprego ou no 2 desempenho de suas atividades diárias?

7. Sentiu-se limitado/a na ocupação habitual dos 2 3 seus tempos livres ou noutras atividades de lazer

8. Teve falta de ar?

$\begin{array}{llll}1 & 2 & 3 & 4 \\ 1 & 2 & 3 & 4 \\ 1 & 2 & 3 & 4 \\ 1 & 2 & 3 & 4 \\ 1 & 2 & 3 & 4 \\ 1 & 2 & 3 & 4\end{array}$

9. Teve dores?

10. Precisou descansar?

11. Teve dificuldade em dormir?

12. Sentiu-se fraco?

13. Teve falta de apetite? 
14. Teve enjoos?

15. Vomitou?

Durante a última semana:

16. Teve prisão de ventre?

17. Teve diarréia?

18. Sentiu-se cansado?

19. As dores perturbaram suas atividades diárias?

20. Teve dificuldade em concentrar-se, por exemplo, para ler o jornal ou ver televisão?

21. Sentiu-se tenso(a)?

22. Teve preocupações?

23. Sentiu-se irritável?

24. Sentiu-se deprimido?

25. Teve dificuldade em lembrar-se das coisas?

26. O seu estado físico ou tratamento médico interferiram na sua vida familiar?

27. O seu estado físico ou tratamento médico interferiram na sua atividade social?

28. O seu estado físico ou tratamento médico causaram-Ihe problemas de ordem finaceira?
Não Um Bastante Muito pouco

$\begin{array}{llll}1 & 2 & 3 & 4 \\ 1 & 2 & 3 & 4 \\ 1 & 2 & 3 & 4 \\ 1 & 2 & 3 & 4 \\ 1 & 2 & 3 & 4\end{array}$

$\begin{array}{llll}1 & 2 & 3 & 4 \\ 1 & 2 & 3 & 4 \\ 1 & 2 & 3 & 4 \\ 1 & 2 & 3 & 4 \\ 1 & 2 & 3 & 4 \\ 1 & 2 & 3 & 4\end{array}$

$2 \quad 3 \quad 4$

$2 \quad 3 \quad 4$

Nas perguntas que se seguem faça um círculo à volta do número, entre 1 e 7, que melhor se aplica ao seu caso

29. Como classificaria a sua saúde em geral durante a última semana?

$\begin{array}{lllllll}1 & 2 & 3 & 4 & 5 & 6 & 7 \\ \text { péssima } & & & & & & \text { ótima }\end{array}$

30. Como classificaria a sua qualidade de vida global durante a última semana?

$\begin{array}{lllllll}1 & 2 & 3 & 4 & 5 & 6 & 7 \\ \text { péssima } & & & & & & \text { ótima }\end{array}$




\section{ANEXO B}

CASCO
A) Questões
1. Sentiu-se limitado/a no seu emprego ou no desempenho de suas atividades diárias? Não
Um pouco
Bastante
Muito

2. Custa-lhe fazer esforços mais violentos, por exemplo, carregar um saco de compras pesado ou uma mala?

Não

Um pouco

Bastante

Muito

3. Tem percebido uma diminuição da força de preensão manual?

Não Um pouco Bastante Muito

4. Você precisa fazer um esforço maior que o comum ao subir escadas?

Não Um pouco Bastante Muito

5. Custa-lhe dar um passeio a pé, fora de casa, aproximadamente $1 \mathrm{~km}$ ?

Não

Um pouco

Bastante

Muito

B) Questionário de Anorexia

1. Meu apetite está

a) muito ruim

b) ruim

c) mais ou menos

d) bom

e) muito bom

2. Quando eu como:

a) eu me sinto cheio depois de comer um pouco

b) eu me sinto cheio depois de comer um terço da comida

c) eu me sinto cheio depois de comer meia refeição

d) eu me sinto cheio depois de comer mais da metade da refeição

3. O sabor dos alimentos

a) muito ruim

b) ruim

c) mais ou menos

d) bom

e) muito bom

4. Normalmente eu como:

a) menos de uma refeição ao dia

b) uma refeição ao dia

c) duas refeições ao dia

d) três refeições ao dia

e) mais que três refeições ao dia

C) Questionário de qualidade de vida

1- Durante o dia você precisa ficar na cama ou na cadeira?

Não Um pouco Bastante

Muito

2- Precisa que o ajudem a comer, a vestir-se, a lavar-se ou a ir ao banheiro? 
Não Um pouco Bastante Muito

3- Sentiu-se limitado/a no seu emprego ou no desempenho de suas atividades diárias?

Não Um pouco Bastante Muito

4- Sentiu-se limitado/a na ocupação habitual dos seus tempos livres ou noutras atividades de lazer

Não Um pouco $\quad$ Bastante $\quad$ Muito

5- Teve falta de ar?

Um pouco $\quad$ Bastante $\quad$ Muito

6- Teve dores?

Um pouco $\quad$ Bastante $\quad$ Muito

7- Precisou descansar?

Não

Um pouco

Bastante

Muito

8- Teve dificuldade em dormir?

Não

Bastante Muito

9- Sentiu-se fraco?

Não Um pouco $\quad$ Bastante $\quad$ Muito

10- Teve falta de apetite?

Não Um pouco $\quad$ Bastante $\quad$ Muito

11 - Teve prisão de ventre?

Não Um pouco $\quad$ Bastante $\quad$ Muito

12- Teve diarréia?

Não

Um pouco

Bastante

Muito

13- As dores perturbaram suas atividades diárias?

Não

Um pouco

Bastante

Muito

14- Sentiu-se irritável?

Não

Um pouco

Bastante Muito

15- Sentiu-se deprimido?

Não Um pouco $\quad$ Bastante $\quad$ Muito

16- Teve dificuldade em concentrar-se, por exemplo, para ler o jornal ou ver televisão? Não

Um pouco

Bastante

Muito

17- Sentiu-se tenso(a)?

Não Um pouco Bastante

18- Teve dificuldade em lembrar-se das coisas?

Não Um pouco Bastante Muito

19- O seu estado físico ou tratamento médico interferiram na sua vida familiar?

Não Um pouco Bastante Muito

20- O seu estado físico ou tratamento médico interferiram na sua atividade social?

Não

Um pouco

Bastante

Muito 
21- O seu estado físico ou tratamento médico causaram-lhe problemas de ordem financeira? Não

Um pouco

Bastante

Muito

22- Com

o você classificaria a sua saúde em geral durante a última semana?
Excelente (1)
Boa (2)
Ruim (3)
Muito ruim (4) 
ANEXO C

TCLE versão Final 17.02.2012

\title{
TERMO DE CONSENTIMENTO LIVRE E ESCLARECIDO
}

\author{
ESTUDO: Influência das citocinas pró- e antiinflamatórias no tecido \\ adiposo branco. Possível interação adipócito e infiltrado mononuclear.
}

Você está sendo convidado(a) a participar do projeto de pesquisa acima citado. O documento abaixo contém todas as informações necessárias sobre a pesquisa que estamos fazendo. Sua colaboração neste estudo será de muita importância para nós, mas se desistir a qualquer momento, isso nâo causará henhum prejuizo a você.

$\mathrm{Eu}$, (inserir o nome, profissão, residente $\mathrm{e}$ domiciliado na, telefone)

portador da Cédula de identidade, RG

, e inscrito no CPF/MF nascido(a) em I , abaixo assinado(a), concordo de livre e espontânea vontade em participar como voluntário(a) do estudo "Influência das citocinas pró- e anti-inflamatórias no tecido adiposo branco. Possivel interação entre o adipócito e o infiltrado mononuclear". Declaro que obtive todas as informações necessárias, bem como todos os eventuais esclarecimentos quanto às dúvidas por mim apresentadas.

Estou ciente que:

I) $\mathrm{O}$ estudo se faz necessário para qu e se possam descobrir as possíveis causas da síndrome denominada caquexia (síndrome caracterizada pela grande perda de peso, força muscular e diminuição do apetite). Será utilizado o sangue e o tecido adiposo branco (localizado subcutaneamente e no omento) para as análises. Esses materiais coletados demonstram-se importantes para o entendimento da etiologia do processo de caquexia. A pesquisa terá duração total de quatro anos, sendo sua participação pontual, ou seja, apenas no ato cirúrgico;

II) Será feita uma coleta de $20 \mathrm{~mL}$ de sangue, no momento do ato cirúrgico, dentro do procedimento de acesso venoso do ato anestésico;

III) Essa coleta será feita apenas para este estudo, em nada influenciará o tratamento e não modificará o procedimento anestésico e cirúrgico;

IV) No dia da internação hospitalar do paciente será realizada coleta de fezes; e durante o procedimento cirúrgico será retirado fragmentos de aproximadamente um grama por tecido (tecido adiposo branco de subcutâneo e de omento, ou seja, tecido adiposo lócalizado subcutaneamente e no omento, respectivamente; fígado e músculo reto do abdome), com tempo total de coleta de aproximadamente 5 minutos. Esse procedimento possui um grau de risco mínimo, não interferindo nos procedimentos padrões da cirurgia; 
V) Essa coleta será feita apenas para este estudo e em nada influenciará o tratamento; não vai me curar; não vai me causar nenhum problema, não haverá nenhum incômodo de dor no momento da coleta;

VI) A participação neste projeto não tem objetivo de me submeter a um tratamento, bem como não me acarretará qualquer despesa pecuniário com relação aos procedimentos médico-clínico-terapêuticos efetuados com o estudo;

VII) Tenho a liberdade de desistir ou de interromper a colaboração neste estudo no momento em que desejar, sem necessidade de qualquer explicação;

VIII) A desistência não cảusará nenhum prejuízo à minha saúde ou bem estar físico. Não virá interferir no atendimento ou tratamento médico;

IX) Os resultados obtidos durante este ensaio serão mantidos em sigilo, mas concordo que sejam divulgados em publicações científicas, desde que meus dados pessoais não sejam mencionados;

X) Caso eu desejar, poderei pessoalmente tomar conhecimento dos resultados, ao final desta pesquisa

( ) Desejo conhecer os resultados desta pesquisa.

( ) Não desejo conhecer os resultados desta pesquisa.

IX. Concordo que o material poderá ser utilizado em outros projetos desde que autorizado pela Comissão de Ética deste Instituto e pelo responsável por esta pesquisa.
( ) Sim
ou
( ) Não

"DECLARO QUE, APÓS CONVENIENTEMENTE ESCLARECIDO PELO PESQUISADOR E TER ENTENDIDO O QUE ME FOI EXPLICADO, CONSINTO EM PARTICIPAR DA PRESENTE PESQUISA".

São Paulo, de de 201

( ) Paciente / ( ) Responsável X.

\section{Testemunha 1:}

$$
\text { Nome / RG / Telefone }
$$

Testemunha 2:

$$
\text { Nome / RG / Telefone }
$$

\section{Responsável pelo Projeto:}

Prof" Dra. Marília Cerqueira Leite Seelaender

Instituto de Ciências Biomédicas I

Telefone para contato: $\quad 3091-7225$

Identificação do CEP-HU: Endereço: Av. Prof. Lineu Preste, 2565 - Cidade Universitária CEP: 05508-000 - São Paulo - SP

Telefones: 3091-9457 - Fax: 3091-9479 - E-mail: cep@hu.usp.br

$$
\begin{aligned}
& \text { Rubrica do sujeito de pesquisa ou responsávol } \\
& \text { Rubrica do pesquisador }
\end{aligned}
$$

